Article

\title{
Contribution of Rhizobium-Legume Symbiosis in Salt Stress Tolerance in Medicago truncatula Evaluated through Photosynthesis, Antioxidant Enzymes, and Compatible Solutes Accumulation
}

\author{
Annie Irshad ${ }^{1}$, Rana Naveed Ur Rehman ${ }^{2}$, Muhammad Mohsin Abrar ${ }^{3}{ }^{\circledR}$, Qudsia Saeed ${ }^{4}$, Rahat Sharif ${ }^{5}$ \\ and Tianming $\mathrm{Hu}^{1, *}$
}

1 College of Grassland Agriculture, Northwest A\&F University, Yangling 712100, China; annie.irshad@outlook.com

2 State Key Laboratory of Crop Stress Biology for Arid Areas, College of Horticulture, Northwest A\&F University, Yangling 712100, China; naveed138@gmail.com

3 National Engineering Laboratory for Improving Quality of Arable Land, Institute of Agricultural Resources and Regional Planning, Chinese Academy of Agricultural Sciences, Beijing 100081, China; randhawasab@hotmail.com

4 College of Natural Resources and Environment, Northwest A\&F University, Yangling 712100, China; syedaqudsia.saeed@yahoo.com

5 College of Horticulture and Plant Protection, Yangzhou University, 48 Wenhui East Road, Yangzhou 225009, China; rahatsharif2016@nwafu.edu.cn

* Correspondence: hutianming@126.com; Tel.: +86-29-8709-0189

Citation: Irshad, A.; Rehman, R.N.U.; Abrar, M.M.; Saeed, Q.; Sharif, R.; Hu, T. Contribution of Rhizobium-Legume Symbiosis in Salt Stress Tolerance in Medicago truncatula Evaluated through Photosynthesis, Antioxidant Enzymes, and Compatible Solutes Accumulation. Sustainability 2021, 13, 3369. https:// doi.org/10.3390/su13063369

Academic Editor: Jun-Ichi Sakagami

Received: 29 January 2021

Accepted: 15 March 2021

Published: 18 March 2021

Publisher's Note: MDPI stays neutral with regard to jurisdictional claims in published maps and institutional affiliations.

Copyright: (c) 2021 by the authors. Licensee MDPI, Basel, Switzerland. This article is an open access article distributed under the terms and conditions of the Creative Commons Attribution (CC BY) license (https:// creativecommons.org/licenses/by/ $4.0 /)$.

\begin{abstract}
The effects of salt stress on the growth, nodulation, and nitrogen $(\mathrm{N})$ fixation of legumes are well known, but the relationship between symbiotic nitrogen fixation (SNF) driven by rhizobiumlegume symbiosis and salt tolerance in Medicago truncatula is not well studied. The effects of the active nodulation process on salt stress tolerance of Medicago truncatula were evaluated by quantifying the compatible solutes, soluble sugars, and antioxidants enzymes, as well as growth and survival rate of plants. Eight weeks old plants, divided in three groups: (i) no nodules (NN), (ii) inactive nodules (IN), and (iii) active nodules (AN), were exposed to $150 \mathrm{mM}$ of $\mathrm{NaCl}$ salt stress for $0,8,16,24,32$, 40 , and $48 \mathrm{~h}$ in hydroponic system. AN plants showed a higher survival rate $(30.83 \%$ and $38.35 \%)$, chlorophyll contents (37.18\% and $44.51 \%)$, and photosynthesis compared to IN and NN plants, respectively. Improved salt tolerance in AN plants was linked with higher activities of enzymatic and nonenzymatic antioxidants and higher $\mathrm{K}^{+}(20.45 \%$ and $39.21 \%)$ and lower $\mathrm{Na}^{+}$accumulations (17.54\% and $24.51 \%$ ) when compared with IN and NN plants, respectively. Additionally, higher generation of reactive oxygen species (ROS) was indicative of salt stress, causing membrane damage as revealed by higher electrolyte leakage and lipid peroxidation. All such effects were significantly ameliorated in AN plants, showing higher compatible solutes (proline, free amino acids, glycine betaine, soluble sugars, and proteins) and maintaining higher relative water contents (61.34\%). This study advocates positive role of Rhizobium meliloti inoculation against salt stress through upregulation of antioxidant system and a higher concentration of compatible solutes.
\end{abstract}

Keywords: Medicago truncatula; antioxidant enzymes; oxidative damage; salt stress; active nodulation; osmolyte accumulation

\section{Introduction}

Global changes have increased abiotic stresses and mounted pressure on agriculture to produce more food from the existing land area to feed the ever-increasing human population. To overcome this challenge, there is a need to bring in large-area cultivation of problematic soils for crop production, such as salt-affected soils, which cover around $20 \%$ of the global irrigated area spreading over 60 million hectares [1]. 
Soil salinity adversely affects growth, survival, and yield of most crops [2,3], typically by prompting numerous physiological, biochemical, and molecular processes involving accumulation of osmoprotectants, sequestering of $\mathrm{Na}^{+}$, and initiation of antioxidative stress responses [4,5]. In response to oxidative damage in plants caused by salt stress, reactive oxygen species (ROS), such as $\mathrm{H}_{2} \mathrm{O}_{2}, \mathrm{O}_{2}{ }^{-\bullet}$ and $\mathrm{OH}^{-}$, are produced. This oxidative damage catalyzes the oxidation of cellular components leading to the damages of membrane and DNA and also causes protein dysfunction [4]. Peroxidase (POD), catalase (CAT), ascorbate peroxidase (APX), glutathione reductase (GR), and superoxide dismutase (SOD) are enzymes responsible for the scavenging of ROS and mainly exist as isoenzymes in different cell organelles such as mitochondria and chloroplasts [6,7]. Moreover, osmolytes accumulation, such as those of proline, glycine betaine, free amino acids, soluble sugars, and proteins, is another metabolic phenomenon to overcome salt-induced stress in plants [8].

Rhizobia are important symbiotic soil bacteria, which possess the ability to induce root nodules on legumes and provide these plants with fixed nitrogen. Rhizobia or nitrogenfixing legumes contribute to nitrogen enrichment of the soil and reduce the need for chemical fertilizers. Symbiosis improves legumes biomass production as well as the productivity of cereals and other crops used in agricultural rotations [9-11]. In symbiotic nitrogen fixation (SNF), rhizobia use carbon and energy sources from plants and in turn provide fixed nitrogen to plants [12]. During this process, rhizobia release chemical molecules that can affect plant growth and yield, including phytohormones, riboflavin, lumichrome, lipo-chito-oligosaccharide nod factors, and hydrogen gas $\left(\mathrm{H}_{2}\right)$ evolved by nitrogenase [13]. It is estimated that rhizobia-legume symbiotic interaction contributes nearly half of the nitrogen fixation in soil ecosystems, thus improving soil fertility [14]. However, saline soil conditions can significantly restrict the nitrogenase activity because of its negative effects on rhizobial activities [15]. It has been reported that salt stress adversely affected rhizobia symbiosis in Medicago truncatula and reduced the nodulation process [16]. Salt stress not only limits plant production but also crippled the normal nodule function in legumes [17].

Apart from providing N, symbiotic nitrogen fixation (SNF) is also believed to enhance plants' ability to withstand stressed environments. For example, root nodules contain a set of enzymes and antioxidant metabolites that avert ROS accumulation and thereby prevent damage of proteins, DNA, and lipids. The nonenzymic antioxidative system is composed of glutathione, tocopherols, ascorbate, and carotenoids, which by donating or accepting electrons can neutralize free radicals [18]. All such effects suggest that rhizobium symbiosis can promote the overall health of plants which can translate into enhanced ability to tolerate abiotic stresses, such as salinity. Therefore, SNF could be studied as an important process to enhance the stress tolerance of crops.

Medicago truncatula is a worldwide well-known leguminous forage crop. It belongs to the family Fabaceae and is considered a nutritious and affordable food. Earlier work mainly focused on salt stress effects on fixation of nitrogen and overall plant growth in legumes, but the significance of rhizobium symbiosis process on salt tolerance capacity of Medicago truncatula is not studied in detail.

Taking the background into account, we hypothesized that, rhizobium inoculation modulates osmolytes, antioxidants, and secondary metabolites for increasing salt stress tolerance, and that rhizobium inoculation mitigates salt stress-induced negative influences on physico-biochemical attributes and growth by mediating ROS, lipid peroxidation, and osmolytes contents. Therefore, in this study, we evaluated (i) the influence of rhizobium inoculation on salt stress tolerance response of Medicago truncatula plants and (ii) the efficacy of rhizobium inoculation on survival rate and ability of plants to deal with osmotic and oxidative disturbances induced by salt stress.

\section{Materials and Methods}

\subsection{Plant Material and Growth Conditions}

A hydroponic experiment was conducted for eight weeks at the research facility of Northwest Agriculture and Forestry University, Yangling. The Medicago truncatula 
(Jemalong A17) seeds, with a germination rate of more than $90 \%$, were sacrificed by immersion in concentrated $\mathrm{H}_{2} \mathrm{SO}_{4}$ for $5 \mathrm{~min}$, and thoroughly washed with distilled water. Afterwards, seeds were surface-sterilized with 5\% sodium hypochlorite for $20 \mathrm{~min}$ and lastly rinsed thoroughly four to five times with distilled water. After scarification, seeds were subjected to vernalization on wet filter paper in Petri dishes (placed for $48 \mathrm{~h}$ at $4{ }^{\circ} \mathrm{C}$, in the dark). After that, Petri dishes were kept in dark in a growth chamber for $48 \mathrm{~h}$ at $23{ }^{\circ} \mathrm{C}$ with $60-70 \%$ relative humidity for seed germination. Five days old seedlings were transferred into pots containing $3 \mathrm{~L}$ of Hoagland's nutrient solution. There were total 63 pots, and each pot had 12 seedlings. The seedlings were kept in a growth chamber by maintaining a $16: 8 \mathrm{~h}$ light:dark cycle, $\left(23 \pm 5^{\circ} \mathrm{C}\right):\left(18 \pm 5^{\circ} \mathrm{C}\right)$ day:night temperature cycle, with a relative humidity of $60 \pm 5 \%$.

Out of the total pots, 42 pots containing 15-days-old seedlings were inoculated with Rhizobium meliloti (Dormal strain), and 21 pots of the seedlings were not inoculated. The noninoculated seedlings were irrigated with one-fourth strength Hoagland nutrient solution every day [19]. The inoculated seedlings were randomly distributed into two groups: (i) AN (active nodules): to allow for the formation of AN (visible as pink color), 21 pots of seedlings were watered with nitrogen-free one-fourth strength of Hoagland solution, and (ii) IN (inactive nodules): the remaining 21 pots of inoculated seedlings were watered with nitrogen-containing one-fourth strength Hoagland solution to develop inactive nodules (white color) [12].

\subsection{Plant Growth and Nodule Characterization}

Before salt stress induction, six pots were randomly selected from each group (NN, IN, and AN) for the examination of nodules, and their nitrogen content was analyzed using the Kjeldahl method. The dry weight of plant biomass was measured before and after salt stress treatments. Nodule volume was measured based on the diameter.

\subsection{Estimation of Physiological Parameters and Measuring Survival Rate}

From the remaining 45 pots, six pots from each group (NN, IN, and AN) containing eight-weeks-old seedlings were exposed to four $\mathrm{NaCl}$ stress treatments: 0 (control), 75, 150, and $300 \mathrm{mM} \mathrm{NaCl}$ for 3 days. For the measurement of electrolyte leakage, fresh leaves were punched and soaked in sterile water at $4{ }^{\circ} \mathrm{C}$ for $2 \mathrm{~h}$. The first conductivity value was taken by a conductivity meter DDS-307 (Leici Corporation, China) and read as L1. The homogenate was boiled at $100{ }^{\circ} \mathrm{C}$ in a water bath for $20 \mathrm{~min}$ and cooled down to room temperature. Then, the second conductivity value was recorded and read as L2 [20]. Relative electrical conductivity was calculated by using the following formula:

$$
\text { Electrolyte leakage }(\%)=(\mathrm{L} 1 / \mathrm{L} 2) \times 100
$$

Relative water content (RWC) was determined by following the method of Ahanger et al. [20] with minor modifications. Fresh leaves of Medicago truncatula were weighed (FW), then soaked into Petri dishes containing sterile water to gain turgidity for $24 \mathrm{~h}$, and turgid weight (TW) was observed. After being oven-dried, the dry weight (DW) was measured. RWC was calculated by using the following formula:

$$
\text { RWC }(\%)=\text { FW }-\mathrm{DW} / \mathrm{TW}-\mathrm{DW} \times 100
$$

Carotenoids and total chlorophyll contents were measured by homogenizing fresh leaves in acetone ( $80 \%$ ) using ice-cooled pestle and mortar. After completing the extraction, the homogenate was filtered, and the volume was adjusted with cold acetone up to $10 \mathrm{~mL}$. Optical densities were observed with a UV-1800 spectrophotometer (Shimadzu, Kyoto, Japan) at 480, 645, and $663 \mathrm{~nm}$ [21]. The chlorophyll contents were calculated using the following equations:

$$
\text { Chl a }\left(\mathrm{mg} \mathrm{g}^{-1} \mathrm{FW}\right)=(13.95 \times \mathrm{D} 663-6.88 \times \mathrm{D} 645) \times 0.005 / \mathrm{W}
$$




$$
\begin{gathered}
\mathrm{Chl} \mathrm{b}\left(\mathrm{mg} \mathrm{g}^{-1} \mathrm{FW}\right)=(24.96 \times \mathrm{D} 645-7.32 \times \mathrm{D} 663) \times 0.005 / \mathrm{W} \\
\text { Total Chl }\left(\mathrm{mg} \mathrm{g}^{-1} \mathrm{FW}\right)=\mathrm{Chla}+\mathrm{Chlb}=(18.08 \times \mathrm{D} 645+6.63 \times \mathrm{D} 663) \times 0.005 / \mathrm{W}
\end{gathered}
$$

where D645 and D663 are the absorbances of the chlorophyll contents at 645 and $663 \mathrm{~nm}$, respectively, and $\mathrm{W}$ is the fresh weight of leaves $(\mathrm{g})$.

Photosynthetic efficiency, transpiration rate, and stomatal conductance were observed in the fully expanded leaf using photosynthesis-apparatus Li-6400 (LI-COR Inc., Lincoln, NE, USA), which maintained photosynthetic photon flux density (PPFD) at $1000 \mu \mathrm{mol} \mathrm{m}{ }^{-2} \mathrm{~s}^{-1}$ and $\mathrm{CO}_{2}$ concentration at $400 \mu \mathrm{mol} \mathrm{CO}_{2} \mathrm{~mol}^{-1}$ [22,23]. RWC, electrolyte leakage, photosynthetic pigments, and gas exchange parameters were measured in all four salt-treated subgroups: 0 (control), 75, 150, and $300 \mathrm{mM} \mathrm{NaCl}$ after 3 days of stress.

The remaining 27 pots containing eight-weeks plants were given the abovementioned concentrations of $\mathrm{NaCl}$ for 10 days. After 10 days, plants were given the original nutrient solution without $\mathrm{NaCl}$ for another 12 days to allow plants to recover from stress. During this recovery period, plants that developed new green shoots or regained their green coloring of leaves were counted as survived plants. The regrowth capacity of plants was determined based on the fresh weight of regenerated shoots after salt stress.

\subsection{Analysis of Enzymatic and Nonenzymatic Antioxidant Enzymes}

Another experiment was conducted with all three groups of seedlings (NN, IN, and AN) mentioned above in Section 2.1, but this time Medicago truncatula plants were exposed to one level of $\mathrm{NaCl}(150 \mathrm{mM})$ salt stress, and biochemical changes were determined at various time intervals: 0 (control), 8, 16, 24, 32, 40, and $48 \mathrm{~h}$. The harvested seedlings were immediately frozen in liquid nitrogen and stored at $-80^{\circ} \mathrm{C}$ for further analysis of osmotic and antioxidants contents, accumulation of secondary metabolites, and other attributes of oxidative stress analysis. All spectrophotometric analyses were conducted on a HITACHI spectrophotometer (UV-3900, Hitachi High-Technologies Corporation, Tokyo, Japan).

Plant leaves of $0.5 \mathrm{~g}$ were grinded in prechilled pestle and mortar, with $5 \mathrm{~mL}$ of $0.1 \mathrm{M}$ potassium phosphate buffer ( $\mathrm{pH} 7.8$ ), and the mixture was poured into a centrifuge tube. The mixture was then centrifuged at $4{ }^{\circ} \mathrm{C}$ for $20 \mathrm{~min}$ at $12,000 \times g$, and the supernatant was taken for the measurement of antioxidant enzymes activities. Superoxide dismutase (SOD, EC, 1.15.1.1) activity was calculated based on the ability to inhibit the reduction of nitroblue tetrazolium (NBT) by superoxide anion generated by the riboflavin system under $4000 \mathrm{~W}$ (light intensity) at $25^{\circ} \mathrm{C}$ [24]. Peroxidase (POD, EC, 1.11.1.7) activity was measured following the method of Bianco and Defez [25], by using guaiacol $\left(\mathrm{C}_{7} \mathrm{H}_{8} \mathrm{O}_{2}\right)$ as an electron donor. Catalase activity (CAT, EC, 1.11.1.6) was determined by observing the conversion rate of $\mathrm{H}_{2} \mathrm{O}_{2}$ into $\mathrm{H}_{2} \mathrm{O}$ and $\mathrm{O}_{2}$ molecules [25]. The glutathione reductase activity (GR, EC, 1.6.4.2) was determined following the method by Palma et al. [18]. Glutathione-dependent oxidation of NADPH was observed at $340 \mathrm{~nm}$ for $2 \mathrm{~min}$. Ascorbate peroxidase activity (APX, EC, 1.11.1.11) was measured by the method of Fan et al. [26], and $\mathrm{H}_{2} \mathrm{O}_{2}$-dependent ascorbate-oxidation was observed at $290 \mathrm{~nm}$ for $3 \mathrm{~min}$.

Ascorbate (AsA) contents were measured by grinding fresh leaves in trichloroacetic acid $(6 \%)$, and the supernatant was thoroughly mixed with di-nitrophenyl-hydrazine $(2 \%)$ and thiourea $(10 \%)$. Followed by the incubation in the water bath for $15 \mathrm{~min}$, samples were cooled, $5 \mathrm{~mL}$ of $\mathrm{H}_{2} \mathrm{SO}_{4}(80 \%)$ was added, and optical density was noted at $530 \mathrm{~nm}$ [20]. The standard curve of AsA was used for calculation. The concentration of reduced glutathione (GSH) was determined following the method of Ahanger et al. [27]. One hundred mg fresh leaf tissues were macerating in phosphate buffer (pH 8.0), and the $500 \mu \mathrm{L}$ supernatant was extracted, which was mixed with 5,5-di-thiobis-2-nitro-benzoic acid. Absorbance was recorded at $412 \mathrm{~nm}$, and lastly, GSH concentration was calculated following the standard graph of GSH. 


\subsection{Profiling Soluble Sugars and Compatible Solutes}

For evaluation of proline content, leaves were homogenized in pestle and mortar, with $3 \%$ sulphosalicylic acid and centrifugated at $3000 \times g$ for $10 \mathrm{~min}$. After centrifugation, $2 \mathrm{~mL}$ of supernatant was taken and mixed with $2 \mathrm{~mL}$ each of ninhydrin reagent and glacial acetic acid, and then it was incubated at $100^{\circ} \mathrm{C}$ for $1 \mathrm{~h}$. Reaction was terminated on an ice bath, and toluene was used for separation of the proline, while absorbance was recorded at $520 \mathrm{~nm}[28]$.

Soluble sugars were determined by using the anthrone method. One hundred mg dry powdered sample was homogenized in $80 \%$ ethanol, and the mixture was centrifugated at $5000 \times g$ for $10 \mathrm{~min}$. One $\mathrm{mL}$ of supernatant was mixed with $4 \mathrm{~mL}$ anthrone $(0.2 \%)$, and optical density was observed at $620 \mathrm{~nm}$ [27]. The same protocol was followed for the evaluation of free amino acids [27]. One hundred $\mu \mathrm{L}$ supernatant was mixed with $1 \mathrm{~mL}$ ninhydrin reagent and incubated for $30 \mathrm{~min}$, and optical density was measured at $570 \mathrm{~nm}[29]$.

For determination of soluble proteins, the Bradford method was used by using BSA as standard, and the absorbance at $595 \mathrm{~nm}$ was taken [30]. For determination of glycine betaine, $500 \mathrm{mg}$ dry powdered sample was added in $20 \mathrm{~mL}$ distilled water, and samples were put on a shaker for overnight at room temperature. After filtration, $0.5 \mathrm{~mL}$ of mixture was mixed with $0.2 \mathrm{~mL}$ cold potassium iodide, and periodide crystals were dissolved in 1,2-dichloroethane and kept for $3 \mathrm{~h}$. Optical density was observed at $365 \mathrm{~nm}$, and the calculation was carried out from the standard curve [28]. Nitric oxide content was determined using the Griess-reagent prepared in an ice-cold sodium-acetate buffer ( $\mathrm{pH} 3.6)$ by following Ahmad et al. [21].

\subsection{Malondialdehyde (MDA) and Hydrogen Peroxide $\left(\mathrm{H}_{2} \mathrm{O}_{2}\right)$ Content}

Fresh leaf tissues were homogenized in trichloroacetic acid $(0.1 \%)$, centrifuged, and the supernatant was thoroughly mixed with thiobarbituric acid $(0.5 \%)$ at $95^{\circ} \mathrm{C}$ for $30 \mathrm{~min}$. $\mathrm{Ab}-$ sorbance was recorded at 532 and $600 \mathrm{~nm}$, and an extinction coefficient $(\varepsilon)$ of $155 \mathrm{mM}^{-1} \mathrm{~cm}^{-1}$ was used for calculation [24]. $\mathrm{H}_{2} \mathrm{O}_{2}$ was measured by employing the potassium iodide (KI) method. For the quantification of $\mathrm{H}_{2} \mathrm{O}_{2}, 100 \mathrm{mg}$ fresh leaf tissues were homogenized in $5 \mathrm{~mL}$ of trichloroacetic acid $(0.1 \%)$ and centrifuged at $10,000 \times g$ for $10 \mathrm{~min}$. Five hundred $\mu \mathrm{L}$ supernatant was mixed with a similar amount of potassium phosphate buffer (pH 7.0) and subsequent addition of $1 \mathrm{~mL}$ KI. After thoroughly mixing, the absorbance was read at $390 \mathrm{~nm}[31]$.

\subsection{Determination of $\mathrm{Na}^{+}$and $\mathrm{K}^{+}$}

$\mathrm{Na}^{+}$and $\mathrm{K}^{+}$were estimated by a flame photometer that was connected with a continuous-flow system (microflow automated continuous-flow analyzer-III, Systea, Anagni (Fr), Italy) as described by Theerawitaya et al. [32].

\subsection{Stress Response Models and Salinity-Tolerance Index}

Yield response variables such as relative yield $\left(\mathrm{Y}_{\mathrm{r}}\right)$ and maximum yield $\left(\mathrm{Y}_{\mathrm{m}}\right)$ were calculated as described by Steppuhn et al. [33] and Abrar et al. [34]. Total plant dry biomass (roots and shoots) was represented as yield $(\mathrm{Y})$, and it was converted to relative yield by using a dividing factor maximum yield that was dependent on the total dry biomass, which is independent of salt stress. The following equation was used to calculate $Y_{r}$ value at each salt stress level in all plant groups.

$$
\mathrm{Y}_{\mathrm{r}}=\mathrm{Y} / \mathrm{Y}_{\mathrm{m}}
$$

On the basis of the best-fitted results and maximum $R^{2}$ values, an exponential decay model was used to evaluate the yield response to salt stress after computing the data in Equation (6):

$$
\mathrm{Y}_{\mathrm{r}}=\mathrm{a} \times e^{\mathrm{b} \times E C i}
$$


where the electrical conductivity of Hoagland's nutrient solution is represented as ECi; a and $b$ are the constants, the former depicting the curve shape and the latter determining the model intensity. The salinity-tolerance ondex (STI) shows the inherent ability of crops to tolerate root-zone salinity as suggested by Abrar et al. [34]. $\mathrm{EC}_{\mathrm{i} 50}$ can be concluded from Equation (7): it is the value of EC at which the yield was reduced to $50 \%$ of the maximum yield. The STI can be estimated as described by Abrar et al. [34].

$$
\mathrm{STI}=\mathrm{EC}_{\mathrm{i} 50} \times(1+\mathrm{b})
$$

\subsection{Statistical Analyses}

The data collected was arranged and analyzed using Microsoft Excel 2017. Significant differences among treatments were tested by one-way analyses of variance (ANOVA) using the general linear model (GLM), and finally, Tuckey's HSD test was used to compare means at $p \leq 0.05$. Statistical analyses were completed using SPSS 20.0 (SPSS Inc., Chicago, IL, USA).

\section{Results}

\subsection{Effect of Rhizobium Symbiosis on Plant Growth and Nodule Characterization}

Phenotypically plants showed a similar growth pattern among three nodulation groups (NN, IN, and AN), and no significant differences were observed in shoot and root dry biomass and nitrogen content before salt stress treatment (Table 1). Maximum nodule weight was observed in the AN group, which was $44.05 \%$ higher than IN plants (Table 1).

Table 1. Effect of rhizobium inoculation on the shoot and root dry weight, plant dry biomass, nodule dry weight, and nitrogen content in Medicago truncatula before salt stress induction. NN, plants with no nodules; IN, plants with inactive nodules; and AN, plants with active nodules. Data is mean $( \pm \mathrm{SE})$ of three replicates, and different letters show significant difference at $p \leq 0.05$.

\begin{tabular}{cccccc}
\hline Treatments & $\begin{array}{c}\text { Shoot Dry Weight } \\
(\mathbf{g})\end{array}$ & $\begin{array}{c}\text { Root Dry Weight } \\
\mathbf{( g )}\end{array}$ & $\begin{array}{c}\text { Plant Dry Biomass } \\
\mathbf{( g )}\end{array}$ & $\begin{array}{c}\text { Nodule Dry Weight } \\
(\mathbf{m g})\end{array}$ & $\begin{array}{c}\text { Nitrogen Content } \\
\left.\mathbf{( g ~ K g}^{-1}\right)\end{array}$ \\
\hline NN & $0.67 \pm 0.04^{\mathrm{a}}$ & $1.06 \pm 0.11^{\mathrm{a}}$ & $1.73 \pm 0.12^{\mathrm{a}}$ & - & $19.21 \pm 0.37^{\mathrm{a}}$ \\
AN & $0.71 \pm 0.07^{\mathrm{a}}$ & $1.09 \pm 0.01^{\mathrm{a}}$ & $1.79 \pm 0.09^{\mathrm{a}}$ & $4.20 \pm 0.23^{\mathrm{a}}$ & $19.56 \pm 0.23^{\mathrm{a}}$ \\
IN & $0.68 \pm 0.06^{\mathrm{a}}$ & $1.08 \pm 0.19^{\mathrm{a}}$ & $1.75 \pm 0.18^{\mathrm{a}}$ & $2.35 \pm 0.40^{\mathrm{b}}$ & $19.83 \pm 0.41^{\mathrm{a}}$ \\
\hline
\end{tabular}

The biomass yield of Medicago truncatula corresponding to salt stress levels is summarized in (Figure $1 \mathrm{~A}-\mathrm{C}$ ). We found that in all groups (NN, IN, and $\mathrm{AN}$ ), the relative biomass was inversely proportional to salt levels. The values of ECi50 and salinity-tolerance index (STI) were 90.24 and $90.96 \mathrm{dS} \mathrm{m}^{-1}$ in NN plants, 117.48 and $118.18 \mathrm{dS} \mathrm{m}^{-1}$ in IN plants, and 167.74 and $168.41 \mathrm{dS} \mathrm{m}^{-1}$ in AN plants, respectively, implying a low vulnerability of Medicago truncatula to salt stress. Close examinations of nodules showed AN plants exhibited pink and larger nodules, while IN plants had white and smaller nodules.

3.2. Effect of Rhizobium Symbiosis on Survival Rate, Relative Water Content, Electrolyte Leakage, Photosynthetic Pigments, and Gas Exchange Parameters

Rhizobium inoculation significantly ameliorated Medicago truncatula shoot regeneration capacity and survivorship under salt stress treatment (Figure 2A,B). All three groups had $100 \%$ survival at control $(0 \mathrm{mM} \mathrm{NaCl})$ and $75 \mathrm{mM}$ of $\mathrm{NaCl}$ salt stress. However, at $150 \mathrm{mM}$ of $\mathrm{NaCl}$ stress, the survival rate was decreased by $47.43 \%, 41.02 \%$, and $14.74 \%$ in NN, IN, and AN plants, respectively (Figure 2A). Relative to AN plants, IN and NN plants exhibited lower fresh weight of shoot during regrowth, under 75 and $150 \mathrm{mM} \mathrm{NaCl}$ stress (Figure 2B). IN plants had the lowest shoot weight under $75 \mathrm{mM}$ of $\mathrm{NaCl}$ stress, whereas they depicted better regrowth capacity as compared to NN plants after $150 \mathrm{mM}$ $\mathrm{NaCl}$ stress. 


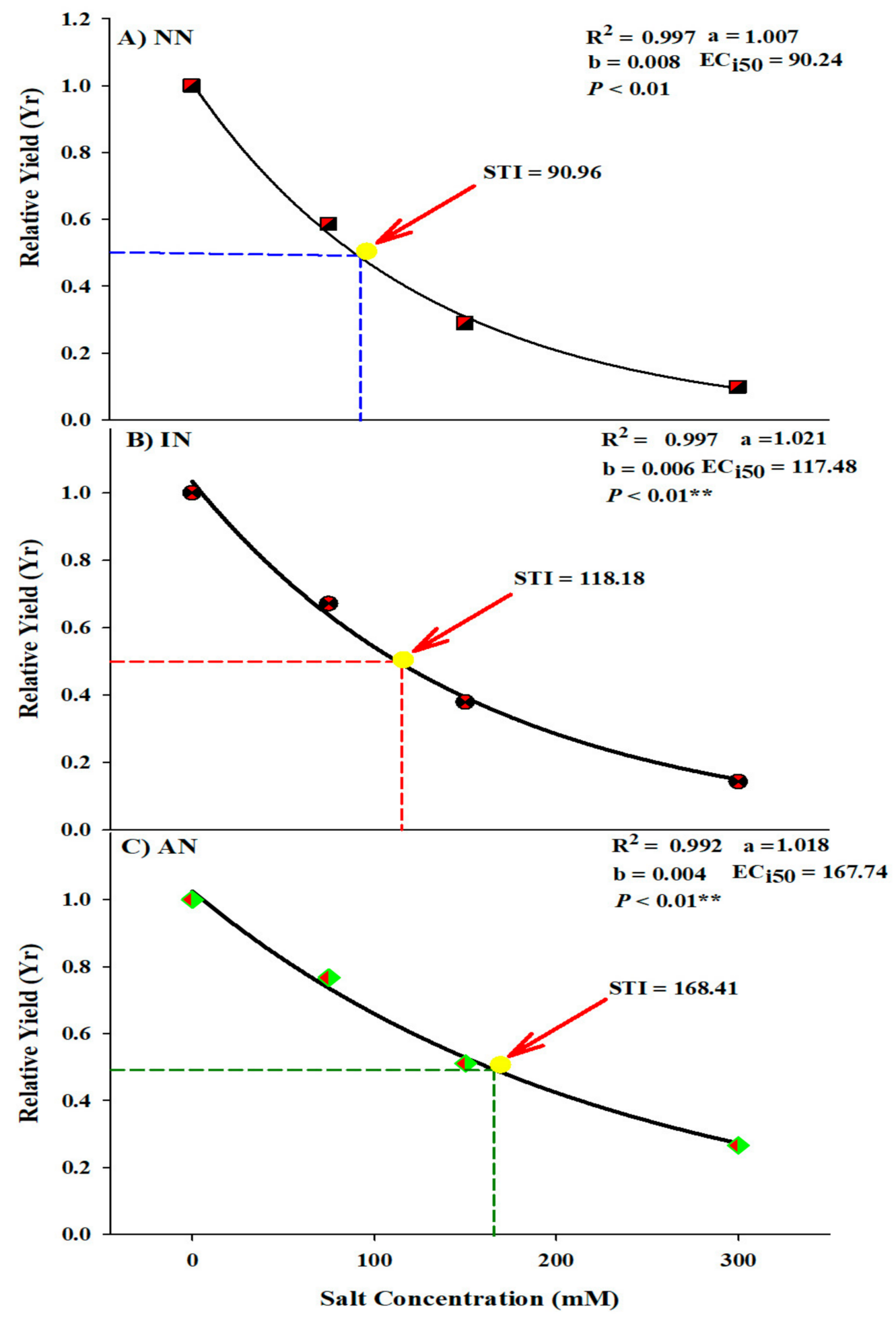

Figure 1. The effect of salt stress on the Medicago truncatula yield (in terms of total dry mass) in NN (A), IN (B), and AN (C) plants. NN, plants with no nodules; IN, plants with inactive nodules; AN, plants with active nodules; STI, stress tolerance index; and $\mathrm{ECi}_{50}$ is the mid-yield salt stress. The yellow circle shows the STI, and the ECi is the electrical conductivity of Hoagland's nutrient solution at the yield reduced to $50 \%$ of the absolute yield (Y). Experimental data (dots). The model curve for $\mathrm{Y}_{\mathrm{r}}=\mathrm{a} \times e^{\mathrm{b}} \times E C i . * *$ indicates significant differences at $p<0.01$. 


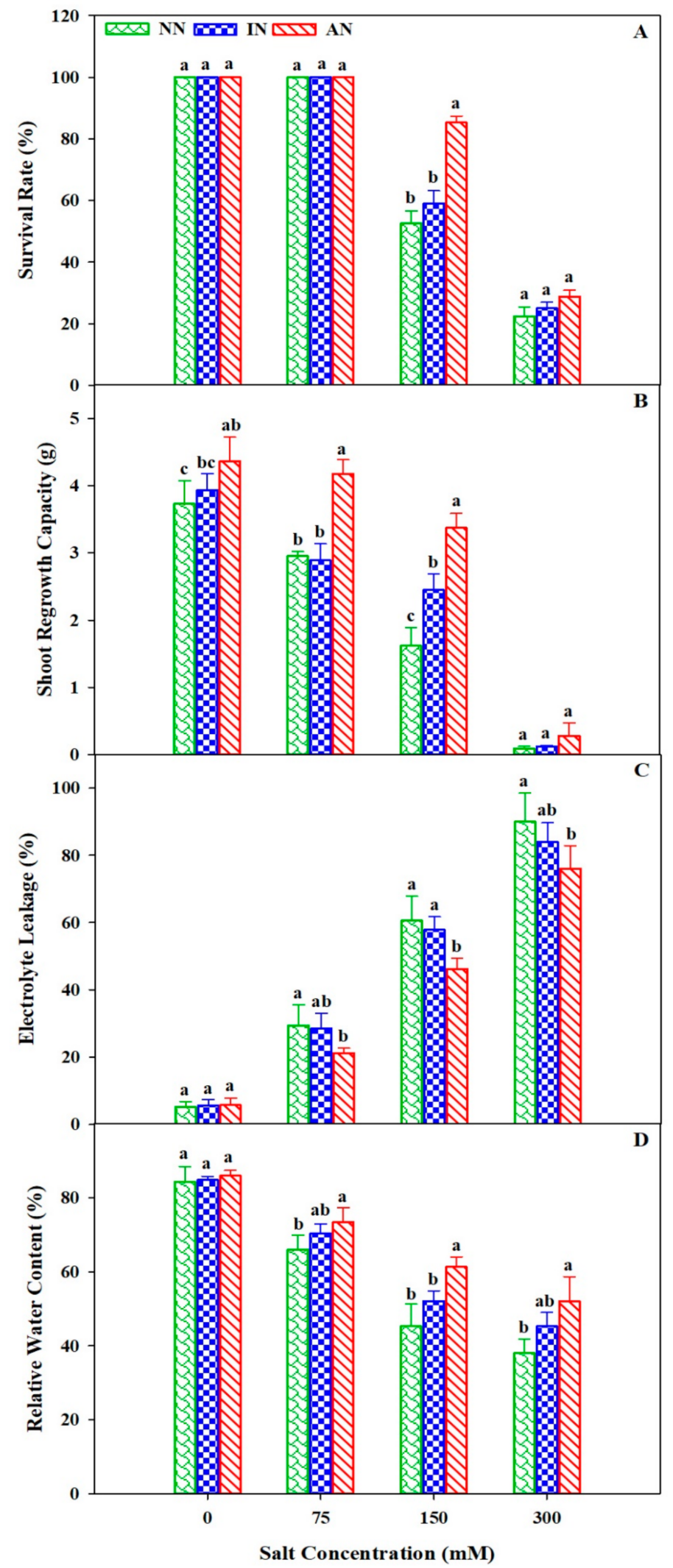

Figure 2. Effect of rhizobium inoculation on survival rate (A), shoot regrowth capacity (B), electrolyte leakage (C), and relative water content (D) of Medicago truncatula under (0, 75, 150, and $300 \mathrm{mM})$ concentrations of salt stress. NN, plants with no nodules; IN, plants with inactive nodules; and AN, plants with active nodules. Data is mean $( \pm \mathrm{SE})$ of three replicates and the same letters along with columns are not significantly different according to Tukey HSD post hoc test after ANOVA $(p \leq 0.05)$. 
Results showed that rhizobium inoculation and salt stress significantly influenced RWC and electrolyte leakage (Figure 2C,D). Compared with the control ( $0 \mathrm{mM}$ ), electrolyte leakage of NN, IN, and AN groups significantly increased with an increase in salt concentration (Figure 2C). Maximum electrolyte leakage was observed at $300 \mathrm{mM}$ level of salt stress. However, at $150 \mathrm{mM}$ the electrolyte leakage was significantly increased by 9.6-fold in NN, 9.1-fold in IN, and 7.1-fold in AN plants, compared to control. RWC was around $85 \%$ in all three groups at control, but it showed a significant decline in NN, IN, and AN plants recording a decrease of $47.27 \%, 39.34 \%$, and $28.64 \%$, respectively, after 3 days of $150 \mathrm{mM}$ stress (Figure 2D).

Salt stress decreased the chlorophyll contents in all plant groups, more prominently in NN (75.79\%) and IN (94.48\%) plants at $300 \mathrm{mM}$ of salt stress, compared with control (Figure $3 \mathrm{~A}$ ). $\mathrm{NaCl}$ treatments reduced chlorophyll contents resulting in declined photosynthetic rate, transpiration rate, and stomatal conductance more severely at $300 \mathrm{mM}$ of $\mathrm{NaCl}$. Moreover, photosynthetic rate, transpiration rate, and stomatal conductance were higher with rhizobium inoculation in AN plants by $42.56 \%, 41.91 \%$, and $13.74 \%$, respectively, compared to NN plants, and by $29.42 \%, 31.71 \%$, and $8.46 \%$, respectively, compared to IN plants, after 3 days of $150 \mathrm{mM}$ stress (Figure 3B-D).

\subsection{Rhizobium Symbiosis Reduced Oxidative Damage}

Lipid peroxidation level influenced nodulation in Medicago truncatula under salt stress (Figure 4A). The MDA content of NN and IN plants was $13.18 \%$ and $22.46 \%$ higher than that of AN plants before salt stress. However, MDA content in NN plants significantly decreased as compared to IN and AN plants after $16 \mathrm{~h}$ of salt stress. In particular, MDA level in NN and IN was 42.35\% and 25.06\% higher than in AN group $24 \mathrm{~h}$ after salt treatment. There was no significant difference in MDA content among all nodulation plant groups (NN, AN, and IN) at 48 h of salt stress (Figure 4A). However, the NN was higher than $\mathrm{AN}$ and IN by $19.33 \%$ and $10.86 \%$, respectively.

Without salt stress, no significant difference was found among NN, IN, and AN group of plants before salt stress and after $8 \mathrm{~h}$ of salt stress (Figure 4B). However, there was a prominent difference in $\mathrm{H}_{2} \mathrm{O}_{2}$ content of $\mathrm{NN}, \mathrm{IN}$, and $\mathrm{AN}$ plants at $24 \mathrm{~h}$ of salt stress, while after $40 \mathrm{~h}$ of stress, AN plants exhibited a significant difference in $\mathrm{H}_{2} \mathrm{O}_{2}$ contents by $30.89 \%$ and sustained a lower level than NN plants.

\subsection{Rhizobium Symbiosis Up-Regulates the Activities of Antioxidant Enzymes}

Before salt stress, no significant difference was observed in SOD activity in all groups. However, the SOD activity in NN and IN was almost similar but significantly higher than AN plants after $8 \mathrm{~h}$ of salt stress (Figure 5A). The SOD activity in AN was higher after $24 \mathrm{~h}$ of stress, while it was low and almost similar in NN and IN. AN plants showed significantly higher SOD activity than NN plants after $32 \mathrm{~h}$ and $48 \mathrm{~h}$ of stress (Figure 5A). The POD activity in AN plants was lower than NN and IN plants before salt treatment (Figure 5B). The POD activity in AN plants displayed an increasing trend with salt stress till $24 \mathrm{~h}$ of salt stress and significantly higher than NN and IN plants by $35.98 \%$ and $15 \%$, respectively. However, at $48 \mathrm{~h}$ of stress, the POD activity of NN plants was significantly higher than IN plants by $10.61 \%$ (Figure 5B).

CAT activity in AN plants was significantly lower compared to IN and NN plants until $16 \mathrm{~h}$ of salt stress and showed an abrupt increase at $24 \mathrm{~h}$ of stress (Figure 5C). After $32 \mathrm{~h}$ of salt stress, the CAT activity of IN and NN plants was significantly decreased by $32.5 \%$ and $16.34 \%$, respectively, compared to AN plants. Before salt stress, the APX activity of IN and AN plants was significantly increased by $26.82 \%$ and $22.46 \%$, respectively, compared to NN plants (Figure 5D). APX activity increased with time in AN and NN plants but decreased in IN plants at $16 \mathrm{~h}$ of stress. After $24 \mathrm{~h}$ of stress, the APX activity was highest in AN plants with an increase of $14.65 \%$ and $25.91 \%$ compared to IN and NN plants, respectively (Figure 5D). APX activity showed decreasing trend after $24 \mathrm{~h}$ in all three plant groups. 


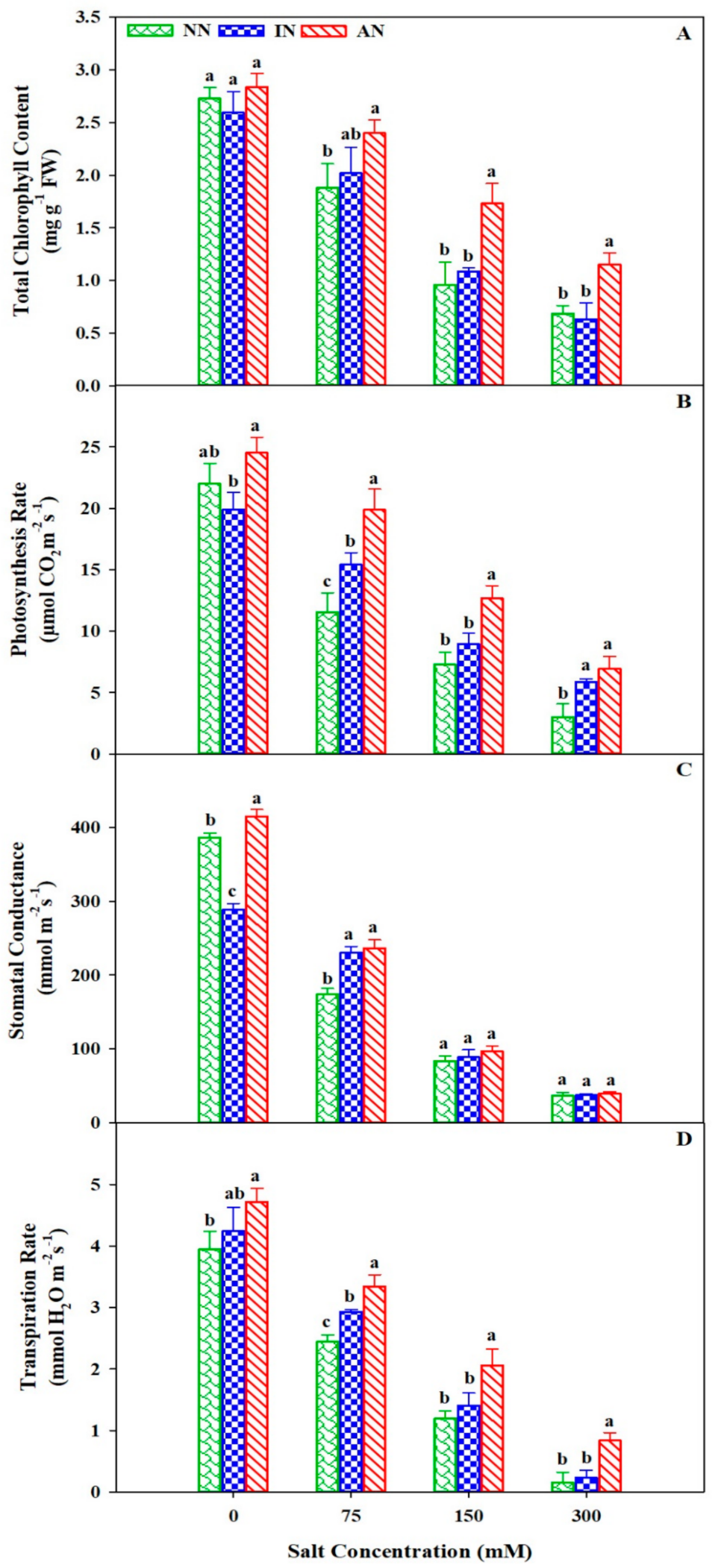

Figure 3. Effect of rhizobium inoculation on total chlorophyll (A), photosynthesis (B), stomatal conductance (C), and transpiration rate (D) in Medicago truncatula under $(0,75,150$, and $300 \mathrm{mM})$ concentrations of salt stress. NN, plants with no nodules; IN, plants with inactive nodules; and AN, plants with active nodules. Data is mean $( \pm S E)$ of three replicates, and the same letters along with columns are not significantly different according to Tukey HSD post hoc test after ANOVA $(p \leq 0.05)$. 


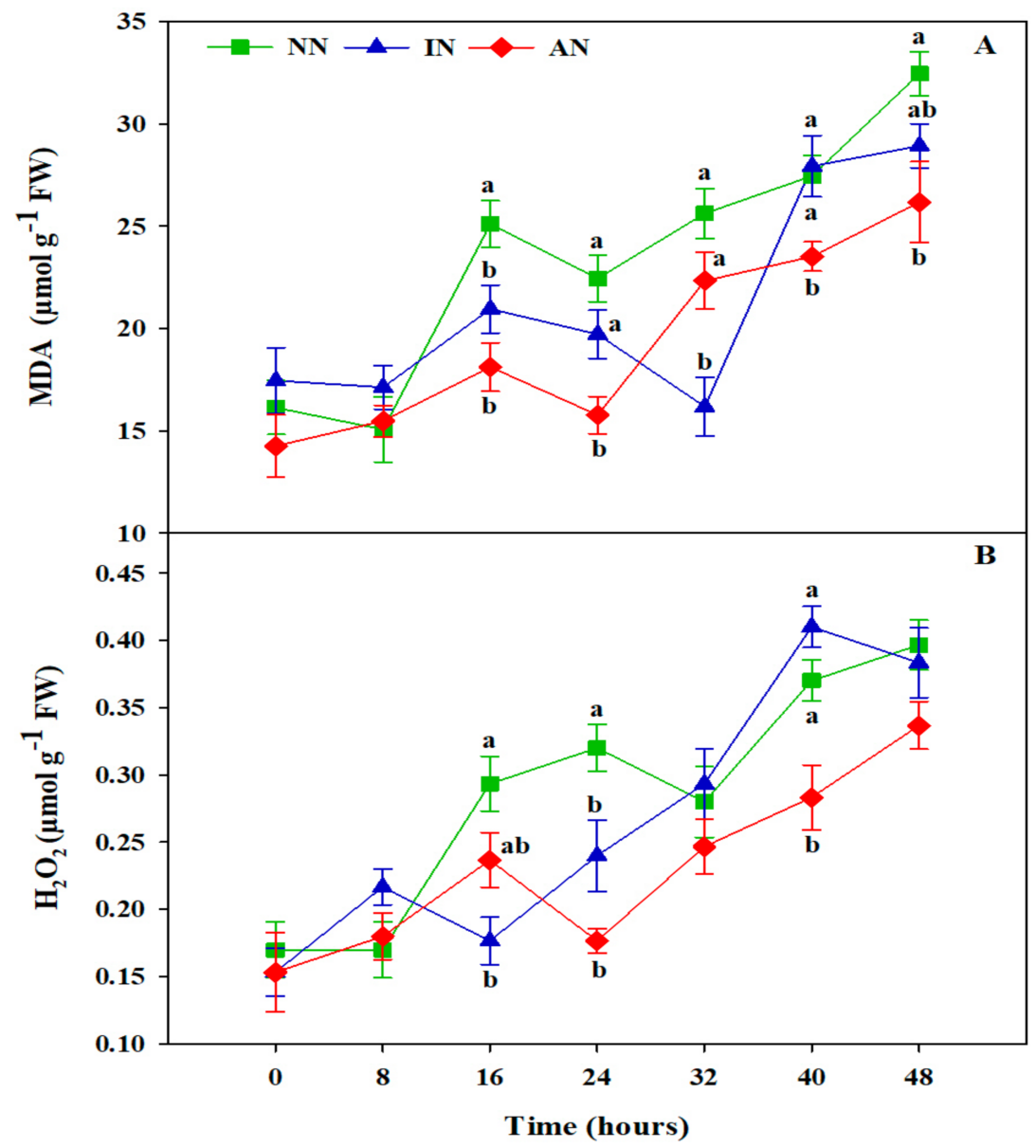

Figure 4. Effect of rhizobium symbiosis on MDA, malondialdehyde (A); and $\mathrm{H}_{2} \mathrm{O}_{2}$, hydrogen peroxide (B) contents in Medicago truncatula plants at different time intervals under $150 \mathrm{mM}$ of salt stress. NN, plants with no nodules; IN, plants with inactive nodules; and AN, plants with active nodules. Data is mean $( \pm S E)$ of three replicates, and the same letters along with columns are not significantly different according to Tukey HSD post hoc test after ANOVA $(p \leq 0.05)$.

\subsection{Effects of Rhizobium Symbiosis on Osmolyte Contents and Nitric Oxide Quantification}

Proline content in Medicago truncatula plants was affected by nodulation (Table 2). Proline content was almost similar in all plant groups before salt treatment but increased significantly during the first $8 \mathrm{~h}$ of stress. At $16 \mathrm{~h}$ of salt stress, the proline content in IN plants was $39.60 \%$ and $52.16 \%$ higher than AN and NN plants, respectively. At $48 \mathrm{~h}$ of stress, the proline content in NN plants was $34.11 \%$ and $32.73 \%$ significantly lower than AN and IN plants, respectively, but no difference was observed among AN and IN plants (Table 2). At $32 \mathrm{~h}$ of salt stress, the glycine betaine content in AN plants was $41.87 \%$ and $53.48 \%$ higher than IN and NN plants, respectively. Glycine betaine content of AN plants was significantly higher than IN and NN plants before and after stressed conditions at all time intervals (Table 2). Glycine betaine contents in IN plants were higher than NN plants but exhibited almost an identical trend to NN plants. The amino acid content of NN plants was minimum and remained lower than the AN and IN group. Amino acids contents in NN plants were almost zero during $0-16 \mathrm{~h}$ of salt stress and increased sharply afterward. Before salt stress, amino acids contents in AN plants were at peak and significantly higher than IN and NN plants by $9.66 \%$ and $90.35 \%$, respectively. Moreover, it increased slightly in AN plants after $8 \mathrm{~h}$ of salt stress followed by a slight decrease and almost remained constant till $32 \mathrm{~h}$ and showed an abrupt increase afterward at $48 \mathrm{~h}$ (Table 2). Amino acid contents in IN plants remained always lower than AN plants, but higher than NN plants, except at $32 \mathrm{~h}$ of stress. 


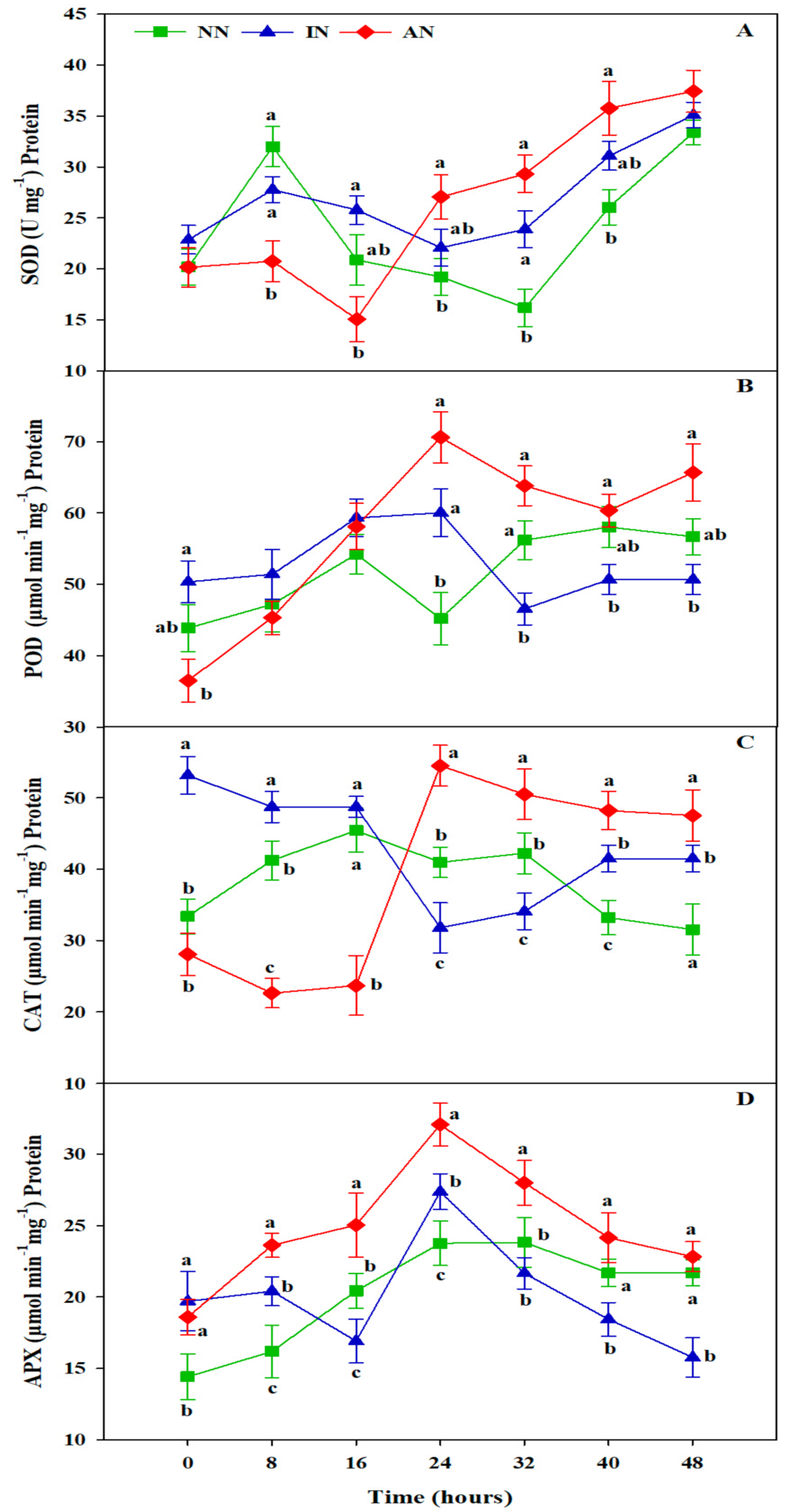

Figure 5. Effect of rhizobium inoculation on SOD, superoxide dismutase (A); POD, peroxidase (B); CAT, catalase (C); and APX, ascorbate peroxidase (D) activity in Medicago truncatula plants at different time intervals under $150 \mathrm{mM}$ of salt stress. NN, plants with no nodules; IN, plants with inactive nodules; and AN, plants with active nodules. Data is mean $( \pm \mathrm{SE})$ of three replicates, and the same letters along with columns are not significantly different according to Tukey HSD post hoc test after ANOVA $(p \leq 0.05)$. 
Table 2. Effect of rhizobium inoculation on proline, glycine betaine, amino acids, soluble sugars and proteins, and nitric oxide in Medicago truncatula subjected to $150 \mathrm{mM}$ of salt stress at different time intervals. Data is mean ( \pm SE) of three replicates, and the same letters along with columns are not significantly different according to Tukey HSD post hoc test after ANOVA $(p \leq 0.05)$.

\begin{tabular}{|c|c|c|c|c|c|c|c|c|}
\hline Osmolytes & Treatment & $0 \mathrm{~h}$ & $8 \mathrm{~h}$ & $16 \mathrm{~h}$ & $24 \mathrm{~h}$ & $32 \mathrm{~h}$ & $40 \mathrm{~h}$ & $48 \mathrm{~h}$ \\
\hline \multirow{3}{*}{$\begin{array}{c}\text { Proline } \\
\left(\mu \mathrm{mol} \mathrm{g}{ }^{-1} \mathrm{DW}\right)\end{array}$} & NN & $0.47 \pm 0.07^{a}$ & $0.15 \pm 0.02^{c}$ & $1.89 \pm 0.1^{b}$ & $3.37 \pm 0.2^{\mathrm{a}}$ & $4.57 \pm 0.1^{a}$ & $3.42 \pm 0.4^{\mathrm{a}}$ & $3.18 \pm 0.1^{b}$ \\
\hline & IN & $0.73 \pm 0.09^{a}$ & $0.95 \pm 0.1^{b}$ & $3.95 \pm 0.2^{a}$ & $2.53 \pm 0.2^{b}$ & $1.44 \pm 0.3^{c}$ & $2.92 \pm 0.2^{a}$ & $4.73 \pm 0.3^{a}$ \\
\hline & $\mathrm{AN}$ & $0.69 \pm 0.1^{a}$ & $1.59 \pm 0.2^{a}$ & $2.39 \pm 0.4^{b}$ & $3.23 \pm 0.1^{a}$ & $2.9 \pm 0.2^{b}$ & $3.64 \pm 0.3^{a}$ & $4.83 \pm 0.2^{\mathrm{a}}$ \\
\hline \multirow{3}{*}{$\begin{array}{l}\text { Glycine Betaine } \\
\left(\mu \mathrm{g} \mathrm{g}^{-1} \mathrm{DW}\right)\end{array}$} & $\mathrm{NN}$ & $4.88 \pm 0.2^{c}$ & $5.23 \pm 0.3^{b}$ & $3.73 \pm 0.6^{c}$ & $9.24 \pm 0.6^{\mathrm{a}}$ & $4.91 \pm 0.4^{b}$ & $7.84 \pm 0.6^{b}$ & $12.14 \pm 0.8^{\mathrm{ab}}$ \\
\hline & IN & $7.21 \pm 0.3^{b}$ & $6.06 \pm 0.2^{b}$ & $5.87 \pm 0.4^{b}$ & $8.57 \pm 0.7^{\mathrm{a}}$ & $6.14 \pm 0.5^{b}$ & $9.57 \pm 0.5^{\mathrm{ab}}$ & $11.37 \pm 0.7^{b}$ \\
\hline & AN & $11.08 \pm 0.4^{\mathrm{a}}$ & $10.29 \pm 0.7^{a}$ & $9.37 \pm 0.4^{\mathrm{a}}$ & $9.9 \pm 0.5^{\mathrm{a}}$ & $10.57 \pm 0.6^{a}$ & $11.28 \pm 0.7^{a}$ & $14.25 \pm 0.8^{a}$ \\
\hline \multirow{3}{*}{$\begin{array}{l}\text { Amino Acids (mg } \\
\left.\qquad \mathrm{g}^{-1} \mathrm{DW}\right)\end{array}$} & $\mathrm{NN}$ & $0.13 \pm 0.02^{c}$ & $0.1 \pm 0.007^{c}$ & $0.08 \pm 0.01^{b}$ & $1.61 \pm 0.1^{b}$ & $2.46 \pm 0.3^{b}$ & $2.77 \pm 0.09^{c}$ & $3.62 \pm 0.7^{a}$ \\
\hline & IN & $1.27 \pm 0.06^{b}$ & $1.38 \pm 0.06^{b}$ & $1.87 \pm 0.08^{a}$ & $1.61 \pm 0.1^{b}$ & $3.16 \pm 0.09^{a}$ & $4.22 \pm 0.2^{a}$ & $3.5 \pm 0.3^{a}$ \\
\hline & $\mathrm{AN}$ & $1.41 \pm 0.07^{a}$ & $2.35 \pm 0.2^{\mathrm{a}}$ & $1.91 \pm 0.1^{\mathrm{a}}$ & $1.99 \pm 0.08^{a}$ & $2.44 \pm 0.08^{b}$ & $3.73 \pm 0.1^{b}$ & $4.04 \pm 0.2^{a}$ \\
\hline \multirow{3}{*}{$\begin{array}{l}\text { Soluble Sugars } \\
\left(\mathrm{mg} \mathrm{g}^{-1} \mathrm{DW}\right)\end{array}$} & $\mathrm{NN}$ & $3.92 \pm 03^{b}$ & $7.31 \pm 0.5^{\mathrm{a}}$ & $4.85 \pm 0.2^{\mathrm{c}}$ & $5.15 \pm 0.1^{c}$ & $13.02 \pm 0.8^{a b}$ & $10.77 \pm 0.9^{b}$ & $12.67 \pm 0.8^{b}$ \\
\hline & IN & $5.13 \pm 0.2^{a}$ & $5.17 \pm 0.9^{a}$ & $10.53 \pm 0.3^{a}$ & $9.61 \pm 0.4^{b}$ & $15.93 \pm 0.7^{a}$ & $17.66 \pm 0.5^{\mathrm{a}}$ & $16.45 \pm 1^{a}$ \\
\hline & $\mathrm{AN}$ & $5.03 \pm 0.3^{a}$ & $4.84 \pm 0.6^{\mathrm{a}}$ & $7.86 \pm 0.7^{b}$ & $13.95 \pm 0.8^{a}$ & $10.68 \pm 0.9^{b}$ & $15.43 \pm 0.8^{a}$ & $19.49 \pm 0.9^{a}$ \\
\hline \multirow{3}{*}{$\begin{array}{l}\text { Soluble Proteins } \\
\left(\mathrm{mg} \mathrm{g}^{-1} \mathrm{DW}\right)\end{array}$} & $\mathrm{NN}$ & $7.26 \pm 0.3^{b}$ & $5.93 \pm 0.9^{b}$ & $13.25 \pm 0.4^{a}$ & $11.98 \pm 0.3^{a}$ & $10.2 \pm 0.5^{b}$ & $7.33 \pm 0.7^{\mathrm{b}}$ & $9.58 \pm 0.6^{b}$ \\
\hline & IN & $8.57 \pm 0.7^{a b}$ & $9.56 \pm 0.8^{a}$ & $9.19 \pm 0.5^{b}$ & $5.9 \pm 0.4^{c}$ & $6.09 \pm 0.6^{c}$ & $9.27 \pm 0.4^{b}$ & $12.15 \pm 0.5^{a}$ \\
\hline & $\mathrm{AN}$ & $9.5 \pm 0.8^{a}$ & $3.93 \pm 0.9^{b}$ & $14.71 \pm 0.9^{a}$ & $7.73 \pm 0.3^{b}$ & $22.41 \pm 0.4^{\mathrm{a}}$ & $18.04 \pm 0.5^{a}$ & $13.94 \pm 0.8^{a}$ \\
\hline \multirow{3}{*}{$\begin{array}{l}\text { Nitric Oxide } \\
\left(\text { nmol g }^{-1} \mathrm{FW}\right)\end{array}$} & $\mathrm{NN}$ & $0.13 \pm 0.06^{b}$ & $0.49 \pm 0.1^{b}$ & $0.65 \pm 0.07^{c}$ & $1.7 \pm 0.3^{b}$ & $0.86 \pm 0.05^{b}$ & $1.11 \pm 0.1^{\mathrm{c}}$ & $1.18 \pm 0.04^{c}$ \\
\hline & IN & $0.4 \pm 0.04^{\mathrm{ab}}$ & $1.64 \pm 0.1^{\mathrm{a}}$ & $1.22 \pm 0.1^{b}$ & $1.89 \pm 0.2^{b}$ & $2.37 \pm 0.05^{a}$ & $2.67 \pm 0.1^{b}$ & $2.98 \pm 0.1^{b}$ \\
\hline & AN & $0.72 \pm 0.1^{\mathrm{a}}$ & $1.26 \pm 0.1^{\mathrm{a}}$ & $1.95 \pm 0.04^{\mathrm{a}}$ & $2.87 \pm 0.1^{\mathrm{a}}$ & $1.76 \pm 0.3^{\mathrm{a}}$ & $3.29 \pm 0.06^{\mathrm{a}}$ & $3.61 \pm 0.04^{\mathrm{a}}$ \\
\hline
\end{tabular}

Soluble sugar content was similar in AN and IN plants but higher than NN plants without salt stress (Table 2). After $16 \mathrm{~h}$ of stress, sugar contents in IN plants were $25.31 \%$ and $53.95 \%$ higher than AN and NN plants, respectively. AN and IN plants showed a nearly similar amount of soluble sugar at $48 \mathrm{~h}$ of salt stress but significantly higher than NN plants (Table 2). No significant difference was observed in soluble protein content among AN, IN, and NN plants before salt treatment (Table 2). After $16 \mathrm{~h}$ of salt stress, the protein content of NN plants gradually decreased and continued till $48 \mathrm{~h}$ of salt stress. However, at $32 \mathrm{~h}$ of salt stress, protein content in AN plants was $54.46 \%$ and $72.81 \%$ higher than NN and IN plants, respectively (Table 2). Nitric oxide content showed an almost similar trend in IN and NN plants, but their contents were lower than AN plant (Table 2). After $24 \mathrm{~h}$ of stress, NO content in AN plants was $40.60 \%$ and $34.1 \%$ higher than $\mathrm{NN}$ and IN plants, respectively. However, IN plants showed a higher NO content than AN and NN plants at $32 \mathrm{~h}$ of salt stress.

\subsection{Effects of Rhizobium Symbiosis on Ascorbate and Reduced Glutathione Content}

Nodulation significantly affected ascorbate (AsA) content during salt stress (Figure 6A). AN plants showed higher AsA content than IN and NN plants during first $8 \mathrm{~h}$ of stress, while, after $24 \mathrm{~h}$ of salt stress, almost the same level of AsA content was observed in AN and IN plants, but both were significantly higher than NN plants. During $32 \mathrm{~h}$ of stress, AN plants showed significantly higher AsA content than NN and IN plants (Figure 6A).

Reduced glutathione (GSH) content was similar among NN, AN, and IN plants during $0-8 \mathrm{hrs}$ of salt stress (Figure 6B). A significant difference was observed at $32 \mathrm{~h}$ of salt stress, where AN plants showed higher GSH content than IN and NN plants showing an increase of $69.95 \%$ and $19.96 \%$, respectively. After $48 \mathrm{~h}$ of stress, AN plants showed a significant difference compared to NN and IN plants. The GR activity of AN plants was significantly higher than IN and NN plants without salt stress and maintained a relatively constant activity for $24 \mathrm{~h}$ of stress. GR activity of AN and IN increased abruptly after $32 \mathrm{~h}$ (Figure 6C). 
There was no change in GR activity of NN plants which remained significantly lower than $\mathrm{AN}$ and IN plants (Figure 6C).

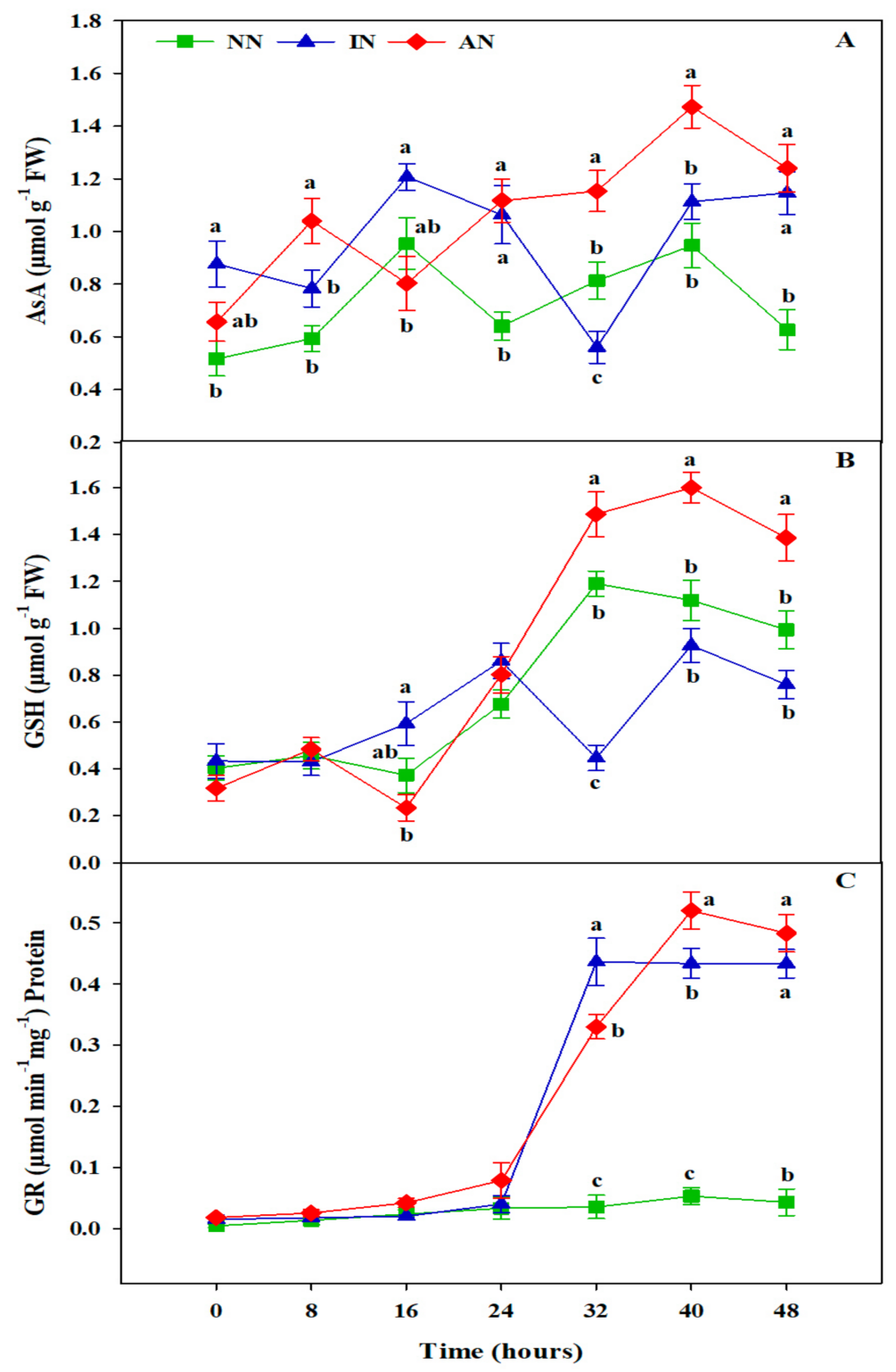

Figure 6. Effect of rhizobium inoculation on AsA, ascorbate (A); GSH, reduced glutathione (B); and GR, glutathione reductase (C) activity in Medicago truncatula plants at different time intervals under $150 \mathrm{mM}$ of salt stress. NN, plants with no nodules; IN, plants with inactive nodules; and AN, plants with active nodules. Data is mean $( \pm S E)$ of three replicates, and the same letters along with columns are not significantly different according to Tukey HSD post hoc test after ANOVA $(p \leq 0.05)$.

\subsection{Rhizobium Symbiosis Reduced $\mathrm{Na}^{+}$Accumulation and Improved $\mathrm{K}^{+}$Uptake}

$\mathrm{Na}^{+}$accumulation was similar among $\mathrm{NN}, \mathrm{AN}$, and IN plants just before the onset of salt stress (Figure 7A). A significant difference was observed at $24 \mathrm{~h}$ of salt stress, where $\mathrm{NN}$ plants showed higher $\mathrm{Na}^{+}$accumulation than IN and AN plants. However, at $40 \mathrm{~h}$ of salt stress, AN plants showed a significant decrease in $\mathrm{Na}^{+}$accumulation compared to $\mathrm{NN}$ and IN plants by $24.51 \%$ and $17.54 \%$, respectively (Figure $7 \mathrm{~A}$ ). $\mathrm{K}^{+}$uptake level was similar among NN, AN, and IN plants at $0 \mathrm{~h}$ (Figure $7 \mathrm{~B}$ ). $\mathrm{K}^{+}$uptake reduced with time after inducing salt stress in all plant groups, even though IN and AN plants maintained higher activities during the first $16 \mathrm{~h}$ of salt stress. At $24 \mathrm{~h}$ of stress, NN plants showed a higher level of $\mathrm{K}^{+}$uptake than $\mathrm{AN}$ and NN plants, while, after $32 \mathrm{~h}$ of stress, $\mathrm{K}^{+}$uptake 
of NN plants was significantly lower than AN plants. After $48 \mathrm{~h}$ of stress, $\mathrm{K}^{+}$uptake of AN plants was $39.21 \%$ and $20.45 \%$ higher than NN and IN plants, respectively (Figure 7B). $\mathrm{K}^{+} / \mathrm{Na}^{+}$ratio in all plant groups displayed the decreasing trend at all time intervals, except in AN plants which showed a significantly higher $\mathrm{K}^{+} / \mathrm{Na}^{+}$ratio (Figure $7 \mathrm{C}$ ).

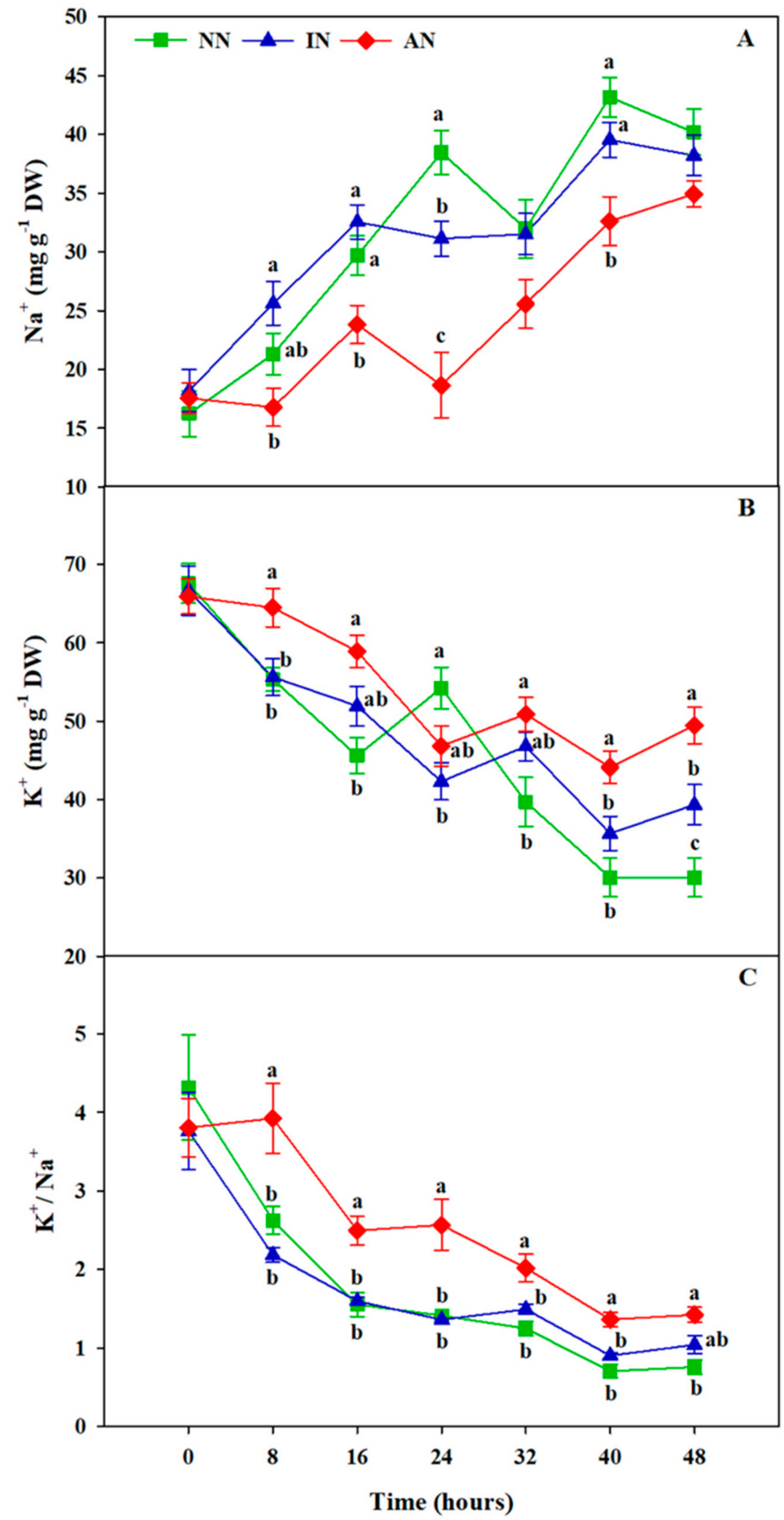

Figure 7. Effect of rhizobium inoculation on $\mathrm{Na}^{+}$, sodium $(\mathbf{A})$; $\mathrm{K}^{+}$, potassium $(\mathbf{B})$; ion concentration, and $\mathrm{K}^{+} / \mathrm{Na}^{+}$ratio $(\mathrm{C})$ in Medicago truncatula plants at different time intervals under $150 \mathrm{mM}$ of salt stress. NN, plants with no nodules; IN, plants with inactive nodules; and AN, plants with active nodules. Data is mean $( \pm \mathrm{SE})$ of three replicates, and the same letters along with columns are not significantly different according to Tukey HSD post hoc test after ANOVA $(p \leq 0.05)$.

\section{Discussion}

The plants having active nodules produced in response to inoculation with Rhizobium meliloti strain maintained better growth and were better able to withstand salt stress 
compared to other plant groups ( $\mathrm{NN}$ and IN). This increased salt tolerance is possibly due to the variation in the nitrogen nutrition levels, since all plant groups possessed nearly the same nitrogen content before salt treatment, and the differences among plant groups were nonsignificant. The viewpoint is additionally supported by improved regrowth capacity of shoots in AN plants at 75 and $150 \mathrm{mM} \mathrm{NaCl}$ treatments, respectively, when compared to NN plants. This suggests that the interaction between Medicago truncatula plants and Rhizobium meliloti fundamentally enhanced salt tolerance. Moreover, by following the $\mathrm{ECi}_{50}$ and STI of AN plants $\left(167.74 \mathrm{dS} \mathrm{m}^{-1}\right.$ and $\left.168.41 \mathrm{dS} \mathrm{m}^{-1}\right)$, it was mathematically proven that AN plants seem to be more resistant to salt stress (Figure 1C) than the NN and IN plants (Figure 1A,B). By observing the $\mathrm{ECi}_{50}$ and STI, Medicago truncatula looks more resistant to other crops, e.g., Jatropha curcas (ECi50 $=10.72 \mathrm{dS} \mathrm{m}^{-1}$, STI $=11.41$ ) and Prunus armeniaca $\left(\mathrm{ECi}_{50}=3.39 \mathrm{dS} \mathrm{m}^{-1}, \mathrm{STI}=4.63\right)$ as stated by Steppuhn et al. [33] and Abrar et al. [34]. However, we also observed that shoot regrowth was also better in AN plants compared to IN plants under the same level of induced salt stress. This could be explained by two points: (i) the physiological responses of AN plants were stronger compared to other plant groups, which suggest that the active nodulation process convert more nutrients for the host plants, which helps tolerate salt stress [24], and (ii) inactive nodules either act as parasites or compete for energy needed by host plants to withstand salt stress. According to Kiers et al. [35], the soybean plant can limit the oxygen supply as a sanction to the rhizobium if it is not fixing the nitrogen. Moreover, some studies have also shown that legumes involving active $\mathrm{N}$ fixation are more tolerant to environmental stress than nodules receiving $\mathrm{N}$ fertilization [36,37].

A plant's ability to tolerate salt stress depends to a large extent on the distribution and absorption of $\mathrm{Na}^{+}$within the plant [38,39]. Hence, plants respond to alleviate or minimize the harmful effects of extra $\mathrm{Na}^{+}$, by maintaining less $\mathrm{Na}^{+}$accumulation in photosynthetic organs and improving $\mathrm{K}^{+}$levels [30]. Less $\mathrm{Na}^{+}$and more $\mathrm{K}^{+}$in the cytoplasm helps in the maintenance and activity of numerous enzymatic processes [40]. It is well known that in many plants, higher $\mathrm{Na}^{+}$is refluxed by SOS1 proteins or through $\mathrm{Na} / \mathrm{H}$ exchangers (NHX) into vacuole at the root levels [41]. Better activities of transport proteins that facilitate sequestration and active compartmentation of $\mathrm{Na}^{+}$ions significantly contribute to better salt stress tolerance in plants [42]. $\mathrm{K}^{+}$is one of the most important macronutrients and is directly involved in many plant processes such as enzyme activation, protein biosynthesis, osmoregulation, and photosynthesis [43]. Horie et al. [44] reported that higher salt concentrations cause increased transport and uptake of $\mathrm{Na}^{+}$and lower $\mathrm{K}^{+}$ content in shoots. The substitution of $\mathrm{K}^{+}$by $\mathrm{Na}^{+}$may lead to nutritional imbalance, which can reduce plants' ability to withstand stress.

Our data indicated that better growth in plants with rhizobium inoculation (AN plants) restricted $\mathrm{Na}^{+}$uptake by $24.51 \%$ and $17.54 \%$ followed by an increase in $\mathrm{K}^{+}$uptake by $39.21 \%$ and $20.45 \%$ than NN and IN plants, respectively (Figure $7 \mathrm{~A}, \mathrm{~B}$ ). Moreover, improving $\mathrm{K}^{+}$uptake increased $\mathrm{K}^{+} / \mathrm{Na}^{+}$ratio in $\mathrm{AN}$ plants at all time intervals (Figure $7 \mathrm{C}$ ). Our results were coherent with Ahanger et al. [30], that nitrogen availability minimized the harmful effects of extra $\mathrm{Na}^{+}$by maintaining less $\mathrm{Na}^{+}$accumulation in photosynthetic organs and improving $\mathrm{K}^{+}$levels which maintained a higher $\mathrm{K}^{+} / \mathrm{Na}^{+}$ratio [30]. Recently, Abdelaal et al. [45] have also demonstrated that foliar application of silicon significantly mitigated salt stress by reducing $\mathrm{Na}^{+}$and increasing $\mathrm{K}^{+}$contents in sweet pepper.

Salinity leads to oxidative stress by increasing the release of ROS species such as $\mathrm{H}_{2} \mathrm{O}_{2}$, which causes lipid peroxidation (MDA) and maintains membrane integrity in plants. Rhizobium inoculation significantly mitigated the adverse effects of salinity-induced ROS. This could be associated with higher nutrient uptake and lower accumulation of ROS in AN plants, which showed a better antioxidative system to face toxic effects of salt stress. In our study, under $150 \mathrm{mM}$ of salt stress, the AN group significantly produced lower lipid peroxidation recorded in terms of MDA content and a lesser production of $\mathrm{H}_{2} \mathrm{O}_{2}$ and EL in comparison to both IN and NN groups (Figures $2 \mathrm{D}$ and $4 \mathrm{~A}, \mathrm{~B}$ ). Similar results were found in two genotypes of faba bean (Vicia faba), where salt stress significantly enhanced $\mathrm{H}_{2} \mathrm{O}_{2}$, 
MDA, and EL in both genotypes [46]. Rhizobium-legume symbiosis may protect lipid membrane by lowering $\mathrm{H}_{2} \mathrm{O}_{2}$ production and alleviating MDA by increasing activities of antioxidant enzymes such as CAT, SOD, and GR, as well as the contents of AsA and GSH. ROS can influence enzymatic activities, plant photosynthetic apparatus, and integrity of cellular membranes $[47,48]$. Nodules contain a set of antioxidant enzymes and metabolites which help avoid the accumulation of ROS and subsequent adverse effects associated with it, including nodule functioning [49]. Higher activity of antioxidant enzymes and their accumulation facilitate the inhibition of lipid peroxidation and in this way, help scavenge ROS. Our results showed that among NN, AN, and IN groups, SOD, CAT, POD, and APX activity were significantly upregulated in the AN plants compared to IN and NN plants (Figure 5A-D). This result is consistent with Bianco and Defez [25] who reported that activities of SOD, POD, and GR were increased, whereas CAT and APX activities were severely deactivated in the leaves of Medicago truncatula plants under salt stress. Studies have documented that an increase in antioxidant enzymes activity after salt stress is a universal phenomenon observed in almost all kinds of crops, such as in cucumber [26], alfalfa [18], soybean [50], and wheat [30].

Oxidative damage (MDA, $\mathrm{H}_{2} \mathrm{O}_{2}$, and $\mathrm{EL}$ ) is closely linked with antioxidative defense machinery. In the first step against ROS generation, SOD comes into the act and converts $\mathrm{O}_{2}$ to $\mathrm{H}_{2} \mathrm{O}_{2}$. This $\mathrm{H}_{2} \mathrm{O}_{2}$ is neutralized by activities of CAT in cytosol, POD activities at the membranes, or by activities of GR and APX in chloroplast and mitochondria through AsAGSH cycle, as suggested by Ahanger and Agarwal [27]. These results might demonstrate why plants with active nodulation process survived adverse conditions better as when $\mathrm{O}_{2}{ }^{-}$levels increased, CAT activity also increased in AN plants leading to a strong response for $\mathrm{H}_{2} \mathrm{O}_{2}$ detoxification [12]. In addition, AN plants also showed higher levels of ASA and GSH accumulation for countering oxidative damage (Figure 6A,B). Similar results were also observed in wheat plants, where AsA and GSH contents were significantly increased resulting in the protection of the photosynthetic electron transport chain by maintaining higher NADP levels and limiting the production of toxic radicals under salt stress [31]. GSH is a low molecule thiol compound in cell regulating scavenging of active oxygen [51] and is also considered to be vital for better development of root nodules. Legumes show a significant positive correlation between nodule GSH and nitrogenase activity with homo-glutathione (h-GSH) contents [52]. Thus, h-GSH concentration controls the efficiency of biological fixation of nitrogen in nodules. Consequently, a deficiency of h-GSH can adversely affect the growth of nodule [53]. In addition to their obvious role in improving nitrogen fixation efficiency, AsA and GSH both regulated the development and growth of plants by upregulating key cellular processes such as cell elongation, senescence, mitosis, etc. [54].

Plants release high contents of osmolytes in the cytosol to avoid the negative effects of osmotic stress induced by salt stress [55]. Amelioration of salinity by improved antioxidant systems in AN plants was further facilitated by the consistent accumulation of compatible osmolytes, including amino acids, proline, glycine betaine, soluble sugars, and soluble proteins (Table 2). Plant species that showed higher osmolytes accumulation had better growth performance and tolerance under stress by maintaining protein functioning and structure and tissue water contents [20]. Consistent with our results, Ahmad et al. [21] reported a higher accumulation of soluble sugars, glycine betaine, proline, and soluble proteins in chickpea under salt stress. Improvement of the osmolytes accumulation is regulated by modulating their assimilatory pathways that are associated with up- and down-regulation of their synthesis and catabolism [30,38,56]. Verdoy et al. [57] have shown that $\mathrm{N}_{2}$ fixation in Medicago truncatula proline accumulation enhanced the plants under salt stress. Compatible solutes like proline and glycine betaine protect plants from damages induced by salt stress because of their role in antioxidant defense and osmoprotectant [29]. Soluble proteins also contribute to osmotic adjustment and source of nitrogen storage [58]. Higher soluble protein accumulation under stress could be due to higher biosynthesis of stress-related specific proteins [28]. Therefore, it is suggested that AN plants through 
improved synthesis and by downregulating the catabolism of osmolytes maintained their higher accumulation under salt stress. Osmolytes accumulation is a ubiquitous response for improving the RWC under salt stress, and rhizobium inoculation-mediated improvement in their accumulation observed in our study explains the beneficial role of active nodules in enhancing the growth performance of Medicago truncatula under salt stress conditions. Higher accumulation of glycine betaine is considered to protect photosynthesis by increasing Rubisco activity under salt stress [59]. Photosynthesis maintains plant growth and subsequently improves plants' ability to tolerate a variety of environmental stresses [60]. Salt stress reduced chlorophyll synthesis, photosynthesis, stomatal conductance, and transpiration rates significantly. However, we found that rhizobium inoculation mitigated that decrease significantly with the impact being much clear due to active nodulation. Our results demonstrated the reduction in chlorophyll content was observed among all groups of Medicago truncatula plants under $\mathrm{NaCl}$ stress (Figure 3A). This reduction in chlorophyll content could partially induce a reduction in biomass yield and growth in all plant groups (NN, AN, and IN). These results are coherent with López et al. [61] that foliage yellowing is generally one of the stress hallmarks, and it is linked with an associated decrease in the contents of photosynthetic pigments [62]. This was also an obvious sign in our study that coincided with an increase in $\mathrm{Na}^{+}$and with the decrease in chlorophyll contents in Medicago truncatula plants. Salt stress causes degradation of pigments by upregulating the activity of chlorophyllase enzyme and downregulating the activities of enzymes linked to chlorophyll biosynthesis in sunflower leaves, which consequently influence the chlorophyll fluorescence and net photosynthesis [63]. Another study showed similar results that salt stress decreases photosynthetic efficiency due to its deleterious impacts on the biosynthesis of chlorophyll's pigment and Rubisco protein [56].

\section{Conclusions}

Our study demonstrates that active nodulation is beneficial for increasing the salttolerance capacity of Medicago truncatula plants mainly through upregulating different antioxidative stress mechanisms and maintaining consistent production of compatible solutes. Plants involving active rhizobium symbiosis had higher survival rates and recovered quickly, which was linked with the active metabolism of antioxidants, osmolytes, and metabolites. There is a need to explore more about the active nitrogen fixation process and whether there are opportunities to further enhance salt tolerance. This can help efficiently utilize problematic salt-affected soils for food production. Therefore, inoculation of Rhizobium meliloti could be a promising strategy for improving salt stress management in the fore coming era of climate change.

Author Contributions: Conceptualization, A.I., T.H.; methodology, A.I.; software, A.I. and R.N.U.R.; validation, A.I., R.N.U.R., T.H.; formal analysis A.I.; investigation, T.H.; resources, T.H.; data curation, A.I.; writing-original draft preparation, A.I., and R.N.U.R.; writing-review and editing, A.I., R.N.U.R., M.M.A., R.S., Q.S., T.H.; supervision, T.H.; project administration, T.H.; funding acquisition, T.H. All authors have read and agreed to the published version of the manuscript.

Funding: This work was supported by the Project of National Natural Science Foundation of China (No.31872411).

Acknowledgments: Laboratory facilities and plant materials provided by College of Grassland Agriculture, Northwest A\&F University, Yangling, China are gratefully acknowledged.

Conflicts of Interest: The authors declare no conflict of interest.

\section{References}

1. Food and Agriculture Organization of the United Nations. Status World's Soil Resources; FAO: Rome, Italy, 2015; 650p, ISBN 978-92-5-109004-6.

2. Mantri, N.; Patade, V.; Penna, S.; Ford, R.; Pang, E. Abiotic stress responses in plants: Present and future. In Abiotic Stress Responses in Plants; Springer: New York, NY, USA, 2012; pp. 1-19. 
3. Niamat, B.; Naveed, M.; Ahmad, Z.; Yaseen, M.; Ditta, A.; Mustafa, A.; Rafique, M.; Bibi, R.; Sun, N.; Xu, M. Calcium-Enriched Animal Manure Alleviates the Adverse Effects of Salt Stress on Growth, Physiology and Nutrients Homeostasis of Zea mays L. Plants 2019, 8, 480. [CrossRef]

4. Bargaz, A.; Zaman-Allah, M.; Farissi, M.; Lazali, M.; Drevon, J.J.; Maougal, R.T.; Georg, C. Physiological and molecular aspects of tolerance to environmental constraints in grain and forage legumes. Int. J. Mol. Sci. 2015, 16, 18976-19008. [CrossRef]

5. Naveed, M.; Sajid, H.; Mustafa, A.; Niamat, B.; Ahmad, Z.; Yaseen, M.; Kamran, M.; Rafique, M.; Ahmar, S.; Chen, J.T. Alleviation of salinity-induced oxidative stress, improvement in growth, physiology and mineral nutrition of canola (Brassica napus L.) through calcium-fortified composted animal manure. Sustainability 2020, 12, 846. [CrossRef]

6. Apel, K.; Hirt, H. Reactive oxygen species: Metabolism, oxidative stress, and signal transduction. Annu. Rev. Plant Biol. 2004, 55, 373-399. [CrossRef]

7. Evelin, H.; Kapoor, R. Arbuscular mycorrhizal symbiosis modulates antioxidant response in salt-stressed Trigonella foenum-graecum plants. Mycorrhiza 2014, 24, 197-208. [CrossRef] [PubMed]

8. Latef, A.A.H.A.; Chaoxing, H. Does inoculation with Glomus mosseae improve salt tolerance in pepper plants? J. Plant Growth Regul. 2014, 33, 644-653. [CrossRef]

9. Graham, P.H.; Vance, C.P. Legumes: Importance and constraints to greater use. Plant Physiol. 2003, 131, 872-877. [CrossRef]

10. Umar, W.; Ayub, M.A.; ur Rehman, M.Z.; Ahmad, H.R.; Farooqi, Z.U.R.; Shahzad, A.; Rehman, U.; Mustafa, A.; Nadeem, M. Nitrogen and Phosphorus Use Efficiency in Agroecosystems. In Resources Use Efficiency in Agriculture; Springer: Singapore, 2020; pp. 213-257.

11. Rafique, M.; Naveed, M.; Mustafa, A.; Akhtar, S.; Munawar, M.; Kaukab, S.; Ali, H.M.; Siddiqui, M.H.; Salem, M.Z. The Combined Effects of Gibberellic Acid and Rhizobium on Growth, Yield and Nutritional Status in Chickpea (Cicer arietinum L.). Agronomy 2021, 11, 105. [CrossRef]

12. Wang, Y.; Zhang, Z.; Zhang, P.; Cao, Y.; Hu, T.; Yang, P. Rhizobium symbiosis contribution to short-term salt stress tolerance in alfalfa (Medicago sativa L.). Plant Soil 2016, 402, 247-261. [CrossRef]

13. Ali, M.A.; Naveed, M.; Mustafa, A.; Abbas, A. The good, the bad, and the ugly of rhizosphere microbiome. In Probiotics and Plant Health; Springer: Singapore, 2017; pp. 253-290.

14. Peoples, M.B.; Craswell, E.T. Biological nitrogen fixation: Investments, expectations and actual contributions to agriculture. Plant Soil 1992, 141, 13-39. [CrossRef]

15. Aranjuelo, I.; Arrese-Igor, C.; Molero, G. Nodule performance within a changing environmental context. J. Plant Physiol. 2014, 171, 1076-1090. [CrossRef]

16. Mhadhbi, H.; Aouani, M.E. Growth and nitrogen-fixing performances of Medicago truncatula-Sinorhizobium meliloti symbioses under salt $(\mathrm{NaCl})$ stress: Micro-and macro-symbiont contribution into symbiosis tolerance. In Biosaline Agriculture and High Salinity Tolerance; Birkhäuser: Basel, Switzerland, 2012; pp. 91-98.

17. López, M.; Herrera-Cervera, J.A.; Iribarne, C.; Tejera, N.A.; Lluch, C. Growth and nitrogen fixation in Lotus japonicus and Medicago truncatula under $\mathrm{NaCl}$ stress: Nodule carbon metabolism. J. Plant Physiol. 2008, 165, 641-650. [CrossRef] [PubMed]

18. Palma, F.; López-Gómez, M.; Tejera, N.A.; Lluch, C. Involvement of abscisic acid in the response of Medicago sativa plants in symbiosis with Sinorhizobium meliloti to salinity. Plant Sci. 2014, 223, 16-24. [CrossRef]

19. Hoagland, D.R.; Arnon, D.I. The Water Culture Method for Growing Plants without Soil. Circular 347; University of California, College of Agriculture: Berkeley, CA, USA, 1950.

20. Ahanger, M.A.; Alyemeni, M.N.; Wijaya, L.; Alamri, S.A.; Alam, P.; Ashraf, M.; Ahmad, P. Potential of exogenously sourced kinetin in protecting Solanum lycopersicum from NaCl-induced oxidative stress through up-regulation of the antioxidant system, ascorbate-glutathione cycle and glyoxalase system. PLoS ONE 2018, 13, e0202175. [CrossRef]

21. Ahmad, P.; Abdel Latef, A.A.; Hashem, A.; Abd_Allah, E.F.; Gucel, S.; Tran, L.S.P. Nitric oxide mitigates salt stress by regulating levels of osmolytes and antioxidant enzymes in chickpea. Front. Plant Sci. 2016, 7, 347. [CrossRef]

22. Dabrowski, P.; Kalaji, M.H.; Baczewska, A.H.; Pawluśkiewicz, B.; Mastalerczuk, G.; Borawska-Jarmułowicz, B.; Paunov, M.; Goltsev, V. Delayed chlorophyll a fluorescence, MR 820, and gas exchange changes in perennial ryegrass under salt stress. $J$. lumin. 2017, 183, 322-333. [CrossRef]

23. Rastogi, A.; Zivcak, M.; Tripathi, D.K.; Yadav, S.; Kalaji, H.M.; Brestic, M. Phytotoxic effect of silver nanoparticles in Triticum aestivum: Improper regulation of photosystem I activity as the reason for oxidative damage in the chloroplast. Photosynthetica 2019, 57, 209-216. [CrossRef]

24. Liu, Y.S.; Geng, J.C.; Sha, X.Y.; Zhao, Y.X.; Hu, T.M.; Yang, P.Z. Effect of rhizobium symbiosis on low-temperature tolerance and antioxidant response in alfalfa (Medicago sativa L.). Front. Plant Sci. 2019, 10, 538. [CrossRef]

25. Bianco, C.; Defez, R. Medicago truncatula improves salt tolerance when nodulated by an indole-3-acetic acid-overproducing Sinorhizobium meliloti strain. J. Exp. Bot. 2009, 60, 3097-3107. [CrossRef]

26. Fan, H.F.; Du, C.X.; Ding, L.; Xu, Y.L. Effects of nitric oxide on the germination of cucumber seeds and antioxidant enzymes under salinity stress. Acta Physiol. Plant. 2013, 35, 2707-2719. [CrossRef]

27. Ahanger, M.A.; Agarwal, R.M. Potassium up-regulates antioxidant metabolism and alleviates growth inhibition under water and osmotic stress in wheat (Triticum aestivum L). Protoplasma 2017, 254, 1471-1486. [CrossRef]

28. Doganlar, Z.B.; Demir, K.; Basak, H.; Gul, I. Effects of salt stress on pigment and total soluble protein contents of three different tomato cultivars. Afr. J. Agric. Res. 2010, 5, 2056-2065. 
29. Hasanuzzaman, M.; Alam, M.; Rahman, A.; Hasanuzzaman, M.; Nahar, K.; Fujita, M. Exogenous proline and glycine betaine mediated upregulation of antioxidant defense and glyoxalase systems provides better protection against salt-induced oxidative stress in two rice (Oryza sativa L.) varieties. BioMed Res. Int. 2014, 2014, 757219. [CrossRef]

30. Ahanger, M.A.; Qin, C.; Begum, N.; Maodong, Q.; Dong, X.X.; El-Esawi, M.; El-Sheikh, M.A.; Alatar, A.A.; Zhang, L. Nitrogen availability prevents oxidative effects of salinity on wheat growth and photosynthesis by up-regulating the antioxidants and osmolytes metabolism, and secondary metabolite accumulation. BMC Plant Biol. 2019, 19, 1-12. [CrossRef]

31. Elkelish, A.A.; Soliman, M.H.; Alhaithloul, H.A.; El-Esawi, M.A. Selenium protects wheat seedlings against salt stress-mediated oxidative damage by up-regulating antioxidants and osmolytes metabolism. Plant Physiol. Bioch. 2019, 137, 144-153. [CrossRef] [PubMed]

32. Theerawitaya, C.; Tisarum, R.; Samphumphuang, T.; Singh, H.P.; Cha-Um, S.; Kirdmanee, C.; Takabe, T. Physio-biochemical and morphological characters of halophyte legume shrub, Acacia ampliceps seedlings in response to salt stress under greenhouse. Front. Plant Sci. 2015, 6, 630. [CrossRef]

33. Steppuhn, H.; Van Genuchten, M.T.; Grieve, C.M. Root-zone salinity: I. Selecting a product-yield index and response function for crop tolerance. Crop Sci. 2005, 45, 209-220. [CrossRef]

34. Abrar, M.M.; Saqib, M.; Abbas, G.; Atiq-ur-Rahman, M.; Mustafa, A.; Shah, S.A.A.; Mehmood, K.; Maitlo, A.A.; Sun, N.; Xu, M. Evaluating the Contribution of Growth, Physiological, and Ionic Components Towards Salinity and Drought Stress Tolerance in Jatropha curcas. Plants 2020, 9, 1574. [CrossRef]

35. Kiers, E.T.; Rousseau, R.A.; West, S.A.; Denison, R.F. Host sanctions and the legume-rhizobium mutualism. Nature 2003, 425, 78-81. [CrossRef]

36. Kirova, E.; Tzvetkova, N.; Vaseva, I.; Ignatov, G. Photosynthetic responses of nitrate-fed and nitrogen-fixing soybeans to progressive water stress. J. Plant Nutr. 2008, 31, 445-458. [CrossRef]

37. El-Akhal, M.R.; Rincón, A.; Coba de la Peña, T.; Lucas, M.M.; El Mourabit, N.; Barrijal, S.; Pueyo, J.J. Effects of salt stress and rhizobial inoculation on growth and nitrogen fixation of three peanut cultivars. Plant Biol. 2013, 15, 415-421. [CrossRef] [PubMed]

38. Porcel, R.; Redondo-Gómez, S.; Mateos-Naranjo, E.; Aroca, R.; Garcia, R.; Ruiz-Lozano, J.M. Arbuscular mycorrhizal symbiosis ameliorates the optimum quantum yield of photosystem II and reduces non-photochemical quenching in rice plants subjected to salt stress. J. Plant Physiol. 2015, 185, 75-83. [CrossRef] [PubMed]

39. Naveed, M.; Ramzan, N.; Mustafa, A.; Samad, A.; Niamat, B.; Yaseen, M.; Ahmad, Z.; Hasanuzzaman, M.; Sun, N.; Shi, W.; et al. Alleviation of salinity induced oxidative stress in Chenopodium quinoa by Fe biofortification and biochar-endophyte interaction. Agronomy 2020, 10, 168. [CrossRef]

40. James, R.A.; Munns, R.; Von Caemmerer, S.; Trejo, C.; Miller, C.; Condon, T. Photosynthetic capacity is related to the cellular and subcellular partitioning of $\mathrm{Na}^{+}, \mathrm{K}^{+}$and $\mathrm{Cl}^{-}$in salt-affected barley and durum wheat. Plant Cell Environ. 2006, 29, $2185-2197$. [CrossRef] [PubMed]

41. Keisham, M.; Mukherjee, S.; Bhatla, S.C. Mechanisms of sodium transport in plants-Progresses and challenges. Int. J. Mol. Sci. 2018, 19, 647. [CrossRef]

42. Zeng, Y.; Li, Q.; Wang, H.; Zhang, J.; Du, J.; Feng, H.; Blumwald, E.; Yu, L.; Xu, G. Two NHX-type transporters from Helianthus tuberosus improve the tolerance of rice to salinity and nutrient deficiency stress. Plant Biotechnol. J. 2018, 16, 310-321. [CrossRef]

43. Shabala, S.; Cuin, T.A. Potassium transport and plant salt tolerance. Physiol. Plantarum 2008, 133, 651-669. [CrossRef] [PubMed]

44. Horie, T.; Motoda, J.; Kubo, M.; Yang, H.; Yoda, K.; Horie, R.; Chan, W.Y.; Leung, H.Y.; Hattori, K.; Konomi, M.; et al. Enhanced salt tolerance mediated by AtHKT1 transporter-induced $\mathrm{Na}^{+}$unloading from xylem vessels to xylem parenchyma cells. Plant J. 2005, 44, 928-938.

45. Abdelaal, K.A.; Mazrou, Y.S.; Hafez, Y.M. Silicon foliar application mitigates salt stress in sweet pepper plants by enhancing water status, photosynthesis, antioxidant enzyme activity and fruit yield. Plants 2020, 9, 733. [CrossRef]

46. Alzahrani, S.M.; Alaraidh, I.A.; Migdadi, H.; Alghamdi, S.; Khan, M.A.; Ahmad, P. Physiological, biochemical, and antioxidant properties of two genotypes of Vicia faba grown under salinity stress. Pak. J. Bot. 2019, 51, 786-798. [CrossRef]

47. Serrano, R.; Mulet, J.M.; Rios, G.; Marquez, J.A.; De Larrinoa, I.F.; Leube, M.P.; Mendizabal, I.; Pascual-Ahuir, A.; Proft, M.; Ros, R.; et al. A glimpse of the mechanisms of ion homeostasis during salt stress. J. Exp. Bot. 1999, 50, 1023-1036. [CrossRef]

48. Saleem, M.H.; Kamran, M.; Zhou, Y.; Parveen, A.; Rehman, M.; Ahmar, S.; Malik, Z.; Mustafa, A.; Anjum, R.M.A.; Wang, B.; et al. Appraising growth, oxidative stress and copper phytoextraction potential of flax (Linum usitatissimum L.) grown in soil differentially spiked with copper. J. Environ. Manag. 2020, 257, 109994. [CrossRef]

49. Matamoros, M.A.; Dalton, D.A.; Ramos, J.; Clemente, M.R.; Rubio, M.C.; Becana, M. Biochemistry and molecular biology of antioxidants in the rhizobia-legume symbiosis. Plant Physiol. 2003, 133, 499-509. [CrossRef]

50. Kataria, S.; Baghel, L.; Jain, M.; Guruprasad, K.N. Magnetopriming regulates antioxidant defense system in soybean against salt stress. Biocatalysis Agric. Biotech. 2019, 18, 101090. [CrossRef]

51. Frendo, P.; Harrison, J.; Norman, C.; Jiménez, M.J.H.; Van de Sype, G.; Gilabert, A.; Puppo, A. Glutathione and homoglutathione play a critical role in the nodulation process of Medicago truncatula. Mol. Plant Microbe Interact. 2005, 18, 254-259. [CrossRef] [PubMed]

52. Groten, K.; Dutilleul, C.; van Heerden, P.D.; Vanacker, H.; Bernard, S.; Finkemeier, I.; Dietz, K.J.; Foyer, C.H. Redox regulation of peroxiredoxin and proteinases by ascorbate and thiols during pea root nodule senescence. FEBS Lett. 2006, 580, 1269-1276. [CrossRef] 
53. El Msehli, S.; Lambert, A.; Baldacci-Cresp, F.; Hopkins, J.; Boncompagni, E.; Smiti, S.A.; Hérouart, D.; Frendo, P. Crucial role of (homo) glutathione in nitrogen fixation in Medicago truncatula nodules. New Phytol. 2011, 192, 496-506. [CrossRef] [PubMed]

54. Tokunaga, T.; Miyahara, K.; Tabata, K.; Esaka, M. Generation and properties of ascorbic acid-overproducing transgenic tobacco cells expressing sense RNA for L-galactono-1, 4-lactone dehydrogenase. Planta 2005, 220, 854-863. [CrossRef] [PubMed]

55. Latef, A.A.H.A.; Miransari, M. The role of arbuscular mycorrhizal fungi in alleviation of salt stress. In Use of Microbes for the Alleviation of Soil Stresses; Springer: New York, NY, USA, 2014; pp. 23-38.

56. Iqbal, N.; Umar, S.; Khan, N.A. Nitrogen availability regulates proline and ethylene production and alleviates salinity stress in mustard (Brassica juncea). J. Plant Physiol. 2015, 178, 84-91. [CrossRef] [PubMed]

57. Verdoy, D.; Coba de la Peña, T.; Redondo, F.J.; Lucas, M.M.; Pueyo, J.J. Transgenic Medicago truncatula plants that accumulate proline display nitrogen-fixing activity with enhanced tolerance to osmotic stress. Plant Cell Environ. 2006, 29, 1913-1923. [CrossRef]

58. Singh, N.K.; Bracker, C.A.; Hasegawa, P.M.; Handa, A.K.; Buckel, S.; Hermodson, M.A.; Pfankoch, E.D.; Regnier, F.E.; Bressan, R.A. Characterization of osmotin: A thaumatin-like protein associated with osmotic adaptation in plant cells. Plant Physiol. 1987, 85, 529-536. [CrossRef] [PubMed]

59. Khan, F.; Hakeem, K.R. Cell signaling during drought and salt stress. In Plant Signaling: Understanding the Molecular Crosstalk; Springer: New Delhi, India, 2014; pp. 227-239.

60. Walters, R.G. Towards an understanding of photosynthetic acclimation. J. Exp. Bot. 2005, 56, 435-447. [CrossRef] [PubMed]

61. López, M.; Tejera, N.A.; Lluch, C. Differential strategies of the model legumes Lotus japonicus and Medicago truncatula in the adaptation to salt stress: Photosynthetic and nutritional responses. Amer. J. Plant Physiol. 2010, 5, 153-162. [CrossRef]

62. Webb, J.A.; Fletcher, R.A. Paclobutrazol protects wheat seedlings from injury due to waterlogging. Plant Growth Regul. 1996, 18, 201-206. [CrossRef]

63. Santos, C.V. Regulation of chlorophyll biosynthesis and degradation by salt stress in sunflower leaves. Sci. Hortic. 2014, 103, 93-99. [CrossRef] 